\title{
Evaluation of HRCLDAS and ERA5 Datasets for Near-Surface Wind over Hainan Island and South China Sea
}

\author{
Yi Jiang ${ }^{1,2}$, Shuai Han ${ }^{3, *}$, Chunxiang Shi ${ }^{3, *}$, Tao Gao ${ }^{2,4}$, Honghui Zhen ${ }^{1,2}$ and Xiaoyan Liu ${ }^{1,2}$ \\ 1 Meteorological Information Center of Hainan Province, Haikou 570203, China; jiangyi251760@cma.cn (Y.J.); \\ zhenghonghui979618@cma.cn (H.Z.); liuxiaoyan849389@cma.cn (X.L.) \\ 2 Key Laboratory of South China Sea Meteorological Disaster Prevention and Mitigation of Hainan Province, \\ Haikou 570203, China; gaotao342560@cma.cn \\ 3 National Meteorological Information Center, Beijing 100081, China \\ 4 Meteorological Observation Center of Hainan Province, Haikou 570203, China \\ * Correspondence: hans@cma.gov.cn (S.H.); shicx@cma.gov.cn (C.S.)
}

Citation: Jiang, Y.; Han, S.; Shi, C.; Gao, T.; Zhen, H.; Liu, X. Evaluation of HRCLDAS and ERA5 Datasets for Near-Surface Wind over Hainan Island and South China Sea. Atmosphere 2021, 12, 766. https:// doi.org/10.3390/atmos12060766

Academic Editors:

Massimiliano Burlando, Rui Salgado, Maria José Monteiro,

Mariana Bernardino, David Carvalho, Flavio T. Couto, Rita M. Cardoso, João P. A. Martins and Joao Carlos Andrade dos Santos

Received: 18 May 2021

Accepted: 11 June 2021

Published: 14 June 2021

Publisher's Note: MDPI stays neutral with regard to jurisdictional claims in published maps and institutional affiliations.

Copyright: (c) 2021 by the authors. Licensee MDPI, Basel, Switzerland. This article is an open access article distributed under the terms and conditions of the Creative Commons Attribution (CC BY) license (https:/ / creativecommons.org/licenses/by/ $4.0 /)$.
Abstract: Near-surface wind data are particularly important for Hainan Island and the South China Sea, and there is a wide range of wind data sources. A detailed understanding of the reliability of these datasets can help us to carry out related research. In this study, the hourly near-surface wind data from the High-Resolution China Meteorological Administration (CMA) Land Data Assimilation System (HRCLDAS) and the fifth-generation ECMWF atmospheric reanalysis data (ERA5) were evaluated by comparison with the ground automatic meteorological observation data for Hainan Island and the South China Sea. The results are as follows: (1) the HRCLDAS and ERA5 near-surface wind data trend was basically the same as the observation data trend, but there was a smaller bias, smaller root-mean-square errors, and higher correlation coefficients between the near-surface wind data from HRCLDAS and the observations; (2) the quality of HRCLDAS and ERA5 near-surface wind data was better over the islands of the South China Sea than over Hainan Island land. However, over the coastal areas of Hainan Island and island stations near Sansha, the quality of the HRCLDAS near-surface wind data was better than that of ERA5; (3) the quality of HRCLDAS near-surface wind data was better than that of ERA 5 over different types of landforms. The deviation of ERA 5 and HRCLDAS wind speed was the largest along the coast, and the quality of the ERA5 wind direction data was poorest over the mountains, whereas that of HRCLDAS was poorest over hilly areas; (4) the accuracy of HRCLDAS at all wind levels was higher than that of ERA5. ERA5 significantly overestimated low-grade winds and underestimated high-grade winds. The accuracy of HRCLDAS wind ratings over the islands of the South China Sea was significantly higher than that over Hainan Island land, especially for the higher wind ratings; and (5) in the typhoon process, the simulation of wind by HRCLDAS was closer to the observations, and its simulation of higher wind speeds was more accurate than the ERA5 simulations.

Keywords: near-surface wind; HRCLDAS; ERA5; evaluation

\section{Introduction}

Near-surface wind is one of the most important meteorological parameters. It is a major factor in various industries of economic importance, such as agriculture, fishery, transportation, construction, and water conservancy engineering. Hainan Province is located at the southernmost tip of China, and it includes Hainan Island and more than two million square kilometers of the South China Sea. Owing to these geographical features, wind disasters occur frequently in Hainan Province, so near-surface wind data are particularly important for Hainan. Although the site observations are accurate, simple site observations cannot meet data needs in areas with sparse sites, such as complex topographic areas and large sea areas [1-4]. With the improvement of numerical models and model interpretation techniques and the diversified requirements of meteorological service 
requirements, refined grid forecasts have gradually replaced traditional site forecasts. Grid live analysis products are the basis of refined grid forecasts [5,6], and they have been widely used in meteorological disaster monitoring, transportation, tourism, agriculture, and other refined meteorological services that are closely related to people's livelihood [7-10]. Comprehensive evaluation needs to be used to judge whether the live analysis products can reflect the actual state of the atmosphere and if they can be used in weather forecasting and meteorological services [11]. Near-surface wind products are an important part of live analysis products [12-14]. Reliable near-surface wind products have an important role in the monitoring, prediction, and study of wind disasters. The evaluation of near-surface wind products can provide the direction for improving the data quality for Hainan, provide basic support for fine-grid forecasting and meteorological services, and help to reduce the losses that are caused by wind disasters.

Data fusion products have been developed in several countries, including the Fifth Generation Global Atmospheric reanalysis data (ERA5) developed by the European Center for medium range weather forecasting (ECMWF), the Interim ECMWF Re-Analysis product (ERA-Interim), the Japanese 55-year Reanalysis (JRA55), the Modern Era Retrospective Analysis for Research and Applications-2 (MERRA2), the National Centers for Environmental Prediction (NCEP)/National Center for Atmospheric Research (NCAR), and so on [15-17]. Many studies have evaluated these data products. Previous studies have shown that the ERA5 surface wind data show the best agreement with in situ observations when compared with ERA-Interim, JRA55, MERRA2, and NCEP/NCAR Reanalysis 1 (R1) [11]. ERA5 has the best performance in terms of the monthly average wind speed magnitude and the interannual variability of near-surface wind speed since 1979 in the Antarctic region [18]. When compared with ERA-Interim, ERA5 is more consistent with observations in terms of average wind speed and gust measurements in Sweden, but there are still significant differences in inland and mountainous areas [19]. ERA5 performs better than ERA-Interim in terms of instantaneous root-mean-square wind speed agreement, mean, and transient wind errors when compared with the ASCAT ocean vector wind observations [20]. There are also studies that have evaluated the applicability of data fusion products in China [21]. ERA-Interim, JRA55, MERRA, and NCEP-2 can reproduce the spatial distribution of the near-surface wind speed and the climatology, but they underestimate the intensity of the near-surface wind speed in most parts of China [22]. Among the surface elements of ERA5, the sea-level pressure and air temperature have the best reproducibility, followed by the relative humidity and wind speed, although the wind speed deviates greatly over coastal areas, and the wind direction has the worst reproducibility [23].

In China, the National Meteorological Information Center (NMIC) developed the HighResolution China Meteorological Administration (CMA) Land Data Assimilation System (HRCLDAS) [24,25]. It can generate high-resolution grid data products of $0.01^{\circ} \times 0.01^{\circ}$ in real time. HRCLDAS data products were released in 2020. Because of its short research and development time, there is still a lack of research evaluating its quality, and the understanding of its accuracy and authenticity in the special geographical environment of Hainan Island and the South China Sea is limited. Therefore, there is an urgent need for a comprehensive inspection and evaluation. To more accurately judge the quality of HRCLDAS products, they need to be compared with data fusion products that are widely recognized and used around the world. Therefore, this study uses ERA5 for comparison with HRCLDAS because of its high resolution and better quality as compared with other similar products around the world [11,18-20], and it discusses the applicability of ERA5 and HRCLDAS near-surface wind products for Hainan Island and the South China Sea.

\section{Materials and Methods}

\subsection{Surface Meteorological Observation Data}

The surface meteorological observation data include the two-minute average wind speed and two-minute average wind direction data after quality control for Hainan Province from 3 April to 31 October 2020 (Table 1). The Hainan Meteorological Infor- 
mation Center provided the data, and they were obtained from the National Comprehensive Meteorological Information Sharing Platform through the MUSIC interface. The stations include two national climate observatories, three national reference climate stations, four national basic meteorological stations, 12 national meteorological observatories, 383 conventional meteorological observatories, and six offshore buoy stations. Figure 1 shows the station distribution.

Table 1. Information on surface meteorological observation data.

\begin{tabular}{|c|c|c|c|c|}
\hline Position & Element & Time Interval & $\begin{array}{c}\text { Number of } \\
\text { Stations }\end{array}$ & Time Range \\
\hline Surface & $\begin{array}{c}10 \mathrm{~m} \text { wind speed } \\
\text { ( } 2 \mathrm{~min} \text { average), } \\
10 \mathrm{~m} \text { wind direction } \\
(2 \mathrm{~min} \text { average })\end{array}$ & Hourly & $\begin{array}{l}410 \text { stations of } \\
\text { Hainan Province }\end{array}$ & $\begin{array}{c}3 \text { April-31 October } \\
2020\end{array}$ \\
\hline
\end{tabular}

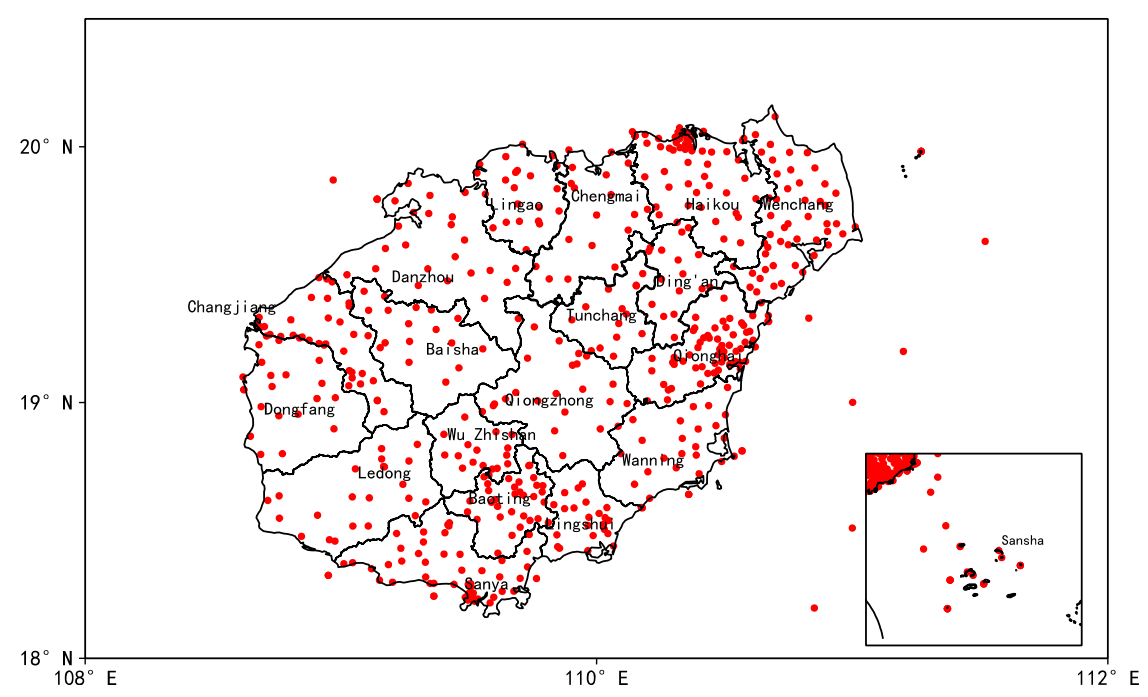

Figure 1. Distribution of ground automatic meteorological observation stations in Hainan Province.

\subsection{ERA5 Near Surface Wind Data Product}

The ERA5 reanalysis data are the latest generation of reanalysis data that were developed by the ECMWF. ERA5 is substantially upgraded and improved when compared with its predecessor ERA-Interim [20,26,27], and it is currently open access. The latitude and longitude grid resolution of the ERA5 reanalysis data is $0.25^{\circ} \times 0.25^{\circ}$, and the time resolution is $1 \mathrm{~h}$. The data are downloaded from the C3S Climate Data Storage (CDS) through ECMWF Web API using Python scripts (Table 2).

Table 2. Information on ERA5 and HRCLDAS data.

\begin{tabular}{|c|c|c|c|c|c|}
\hline Item & Position & Element & Resolution $/^{\circ}$ & $\begin{array}{c}\text { Time } \\
\text { interval }\end{array}$ & Time Range \\
\hline ERA5 & Surface & $\begin{array}{l}10 \mathrm{~m} \mathrm{U} \text { wind, } \\
10 \mathrm{mV} \text { wind }\end{array}$ & 0.25 & Hourly & $\begin{array}{c}3 \text { April-31 } \\
\text { October } 2020\end{array}$ \\
\hline HRCLDAS & Surface & $\begin{array}{l}10 \mathrm{~m} \mathrm{U} \text { wind, } \\
10 \mathrm{mV} \text { wind }\end{array}$ & 0.01 & Hourly & $\begin{array}{c}3 \text { April-31 } \\
\text { October } 2020\end{array}$ \\
\hline
\end{tabular}

\subsection{HRCLDAS Near Surface Wind Data Product}

HRCLDAS is a high-resolution land surface data assimilation system that was developed by the National Meteorological Information Center of the CMA. The system uses multiple grid variational technology [28] and a terrain correction algorithm, combined with 
numerical prediction data, satellite data, and site observation data, to generate atmosphericdata-driven products [24]. The latitude and longitude grid resolution of the HRCLDAS data (Table 2) is $0.01^{\circ} \times 0.01^{\circ}$, and the time resolution is $1 \mathrm{~h}$. The data were obtained from the CMA Data Service Centre.

\subsection{Methodology}

In this study, the surface meteorological observation data are regarded as the "true value", and the HRCLDAS and ERA5 data are interpolated to each station using the nearestneighbor interpolation method. The bias, root-mean-square error (RMSE), and correlation coefficient (COR) between the interpolation results and observations are calculated to judge the quality of the products $[19,22,23]$. For wind speed, the $U$ wind component, and the $V$ wind component, the evaluation index formulas are:

$$
\begin{gathered}
\text { Bias }=\frac{1}{N} \sum_{i=1}^{N}\left(G_{i}-O_{i}\right) \\
R M S E=\sqrt{\frac{1}{N} \sum_{i=1}^{N}\left(G_{i}-O_{i}\right)^{2}} \\
C O R=\frac{\sum_{i=1}^{N}\left(G_{i}-\bar{G}\right)\left(O_{i}-\bar{O}\right)}{\sqrt{\sum_{i=1}^{N}\left(G_{i}-\bar{G}\right)^{2}} \sqrt{\sum_{i=1}^{N}\left(O_{i}-\bar{O}\right)^{2}}}
\end{gathered}
$$

The wind direction is a scalar of the cycle from 0 to 360 degrees, and the absolute value of the error does not exceed 180 degrees. The evaluation index formulas for the wind direction are:

$$
\begin{gathered}
\text { Err }=\left\{\begin{array}{cc}
G_{i}-O_{i} & \left|G_{i}-O_{i}\right| \leq 180 \\
\left(G_{i}-O_{i}\right)\left(1-\frac{360}{\left|G_{i}-O_{i}\right|}\right) & \left|G_{i}-O_{i}\right|>180
\end{array}\right. \\
\text { Bias }=\frac{1}{N} \sum_{i=1}^{N} E r r \\
\text { RMSE }=\sqrt{\frac{1}{N} \sum_{i=1}^{N} \operatorname{Err}^{2}} \\
\text { COR }=\frac{\sum_{i=1}^{N}\left(G_{i}-\bar{G}\right)\left(O_{i}-\bar{O}\right)}{\sqrt{\sum_{i=1}^{N}\left(G_{i}-\bar{G}\right)^{2}} \sqrt{\sum_{i=1}^{N}\left(O_{i}-\bar{O}\right)^{2}}}
\end{gathered}
$$

Here, $O_{i}$ is the site observation value, $G_{i}$ is the value obtained by interpolating the HRCLDAS or ERA5 data to the inspection site, and $N$ is the total number of samples that participate in the inspection.

For the wind speed, the wind grade of the HRCLDAS data and observed data is determined according to the magnitude for the wind speed of each hour. Table 3 shows the classification of wind power.

Table 3. Wind grade classification table.

\begin{tabular}{cccccc}
\hline Wind Grade & $\begin{array}{c}\text { Wind } \\
\text { Speed(m/s) }\end{array}$ & Wind Grade & $\begin{array}{c}\text { Wind } \\
\text { Speed(m/s) }\end{array}$ & Wind Grade & $\begin{array}{c}\text { Wind } \\
\text { Speed(m/s) }\end{array}$ \\
\hline 0 & $0.0-0.2$ & 6 & $10.8-13.1 .8$ & 12 & $32.7-36.9$ \\
1 & $0.3-1.5$ & 7 & $13.1 .9-17.1$ & 13 & $37.0-41.4$ \\
2 & $1.6-3.1 .3$ & 8 & $17.2-20.7$ & 14 & $41.5-46.1$ \\
3 & $3.1 .4-5.4$ & 9 & $20.8-24.4$ & 15 & $46.2-50.9$ \\
4 & $5.5-7.9$ & 10 & $24.5-28.4$ & 16 & $51.0-56.0$ \\
5 & $8.0-10.7$ & 11 & $28.5-32.6$ & 17 & $\geq 56.1$ \\
\hline
\end{tabular}


The accuracy $(A C)$, the strong rate $(F S)$, and the weak rate $(F W)$ of the wind grade are evaluated and analyzed by comparing the wind grade of HRCLDAS with the observed data. The formulas are as follows:

$$
\begin{aligned}
A C_{k} & =\frac{N R_{k}}{N F_{k}} \\
F S_{k} & =\frac{N S_{k}}{N F_{k}} \\
F W_{k} & =\frac{N W_{k}}{N F_{k}}
\end{aligned}
$$

Here, $k$ represents the wind classification inspection level, $N R_{k}$ is the number of correct stations for the wind level inspection at level $k, N R_{k}$ is the number of the strong wind level inspection stations at level $k, N W_{k}$ is the number of the weak wind level inspection stations at level $k$, and $N F_{k}$ is the total number of wind power inspection stations at level $k$.

\section{Results}

\subsection{Analysis of Time Series Variation}

The time series of the daily average wind speed (Figure 2a), wind orientation (Figure 2e), $U$ wind component (Figure 2i), and $V$ wind component (Figure $2 \mathrm{~m}$ ) for Hainan Island and the South China Sea from April to October 2020 were analyzed. The trend of the ERA5 and HRCLDAS wind products over time is basically the same as the observation data trend. For the HRCLDAS data, the time series of the four wind products closely follow the observations. However, the ERA5 data show a much larger variation for the four wind products when compared with the observations: the wind speed is significantly overestimated, but the wind direction is close to the observations; the $U$ component is underestimated most of the time, and the $V$ component is significantly overestimated.

Figure $2 b, f, j, n$ shows the time series charts of the daily average RMSE for wind speed, wind direction, $U$ component, and $V$ component, respectively. The RMSE of the four wind products for HRCLDAS is lower than that for ERA5. From April to September, the RMSE of the HRCLDAS wind speed was largely within the range from 0.2 to $1 \mathrm{~m} \mathrm{~s}^{-1}$, and the RMSE of the ERA5 wind speed was mostly within the range from 1 to $4 \mathrm{~m} \mathrm{~s}^{-1}$. The wind speed in October was significantly higher than that from April to September, and the RMSE of HRCLDAS also improved in October, with values between approximately 1 and $2 \mathrm{~m} \mathrm{~s}^{-1}$. The RMSE of ERA5 improved more significantly than HRCLDAS in October, with values that were between approximately 3 and $6 \mathrm{~m} \mathrm{~s}^{-1}$. From April to September, the RMSE of the HRCLDAS wind direction was mainly concentrated between $30^{\circ}$ and $60^{\circ}$, and the RMSE of the ERA5 wind direction was mainly concentrated in the range from $60^{\circ}$ to $90^{\circ}$. In October, the RMSE of both wind directions decreased significantly, and the decrease of ERA5 was greater than that of HRCLDAS. The RMSE of the HRCLDAS $U$ and $V$ components was similar to that of wind speed, and most were within $1 \mathrm{~m} \mathrm{~s}^{-1}$. For ERA5, the RMSE of the $V$ component was obviously larger than that of the $U$ component, and the variation was larger.

The daily average COR of HRCLDAS wind speed from April to October (Figure 2c) was mostly between 0.9 and 1.0, while that of ERA5 was mostly below 0.6. The COR of the wind direction of the two datasets (Figure $2 \mathrm{~g}$ ) was lower than that of the wind speed, the COR of HRCLDAS was between 0.4 and 0.8 , and that of ERA5 was less than 0.4 with occasional negative correlations. The COR of the $U$ component (Figure $2 \mathrm{k}$ ) and $V$ component (Figure 2o) for the HRCLDAS data were similar, whereas the COR of the $V$ component for the ERA5 data was slightly better than that of the $U$ component. 
(a)

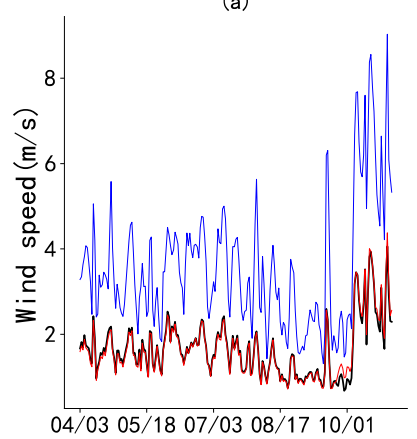

(e)

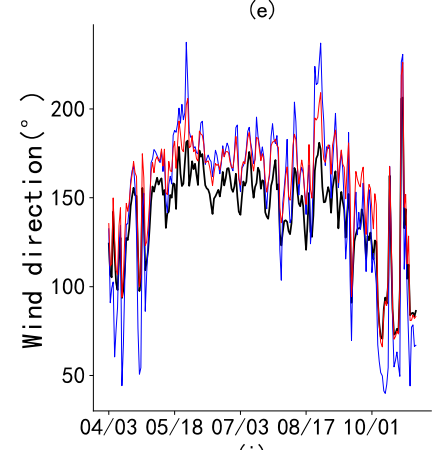

(i)
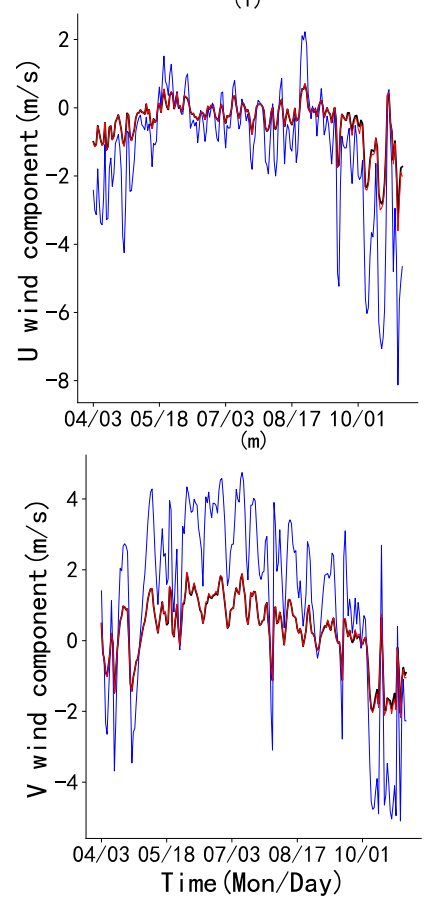

(b)

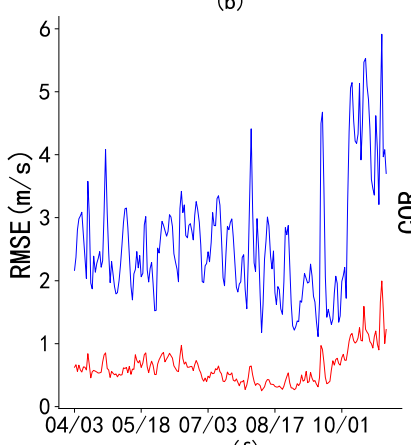

(f)

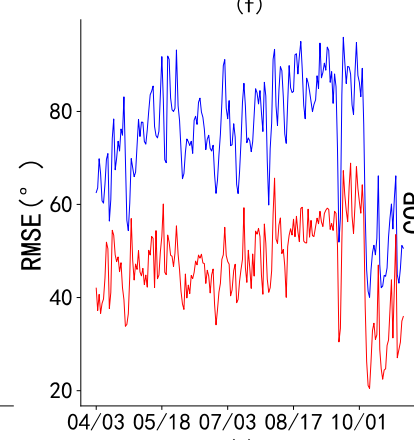

(j)
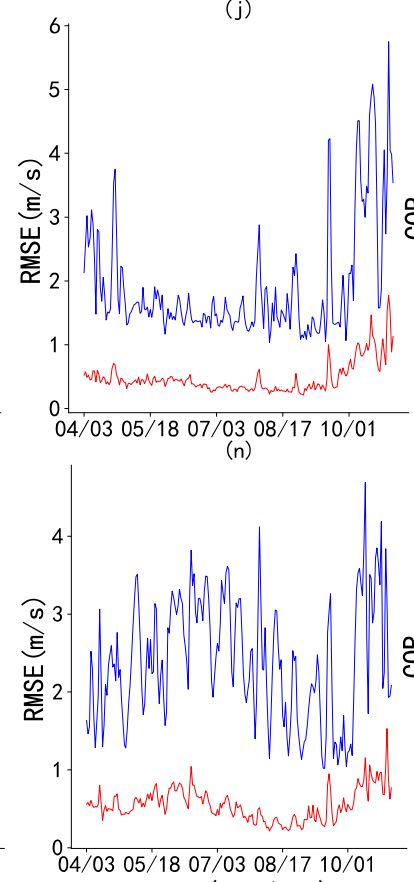

(c)

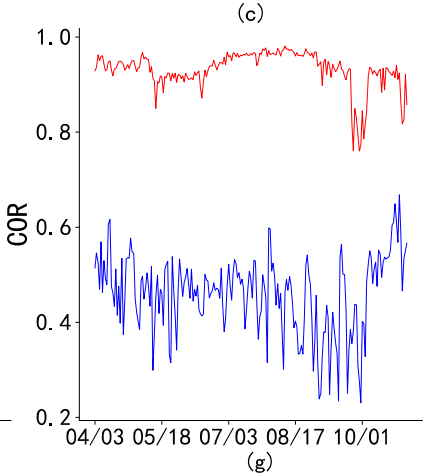

(d)

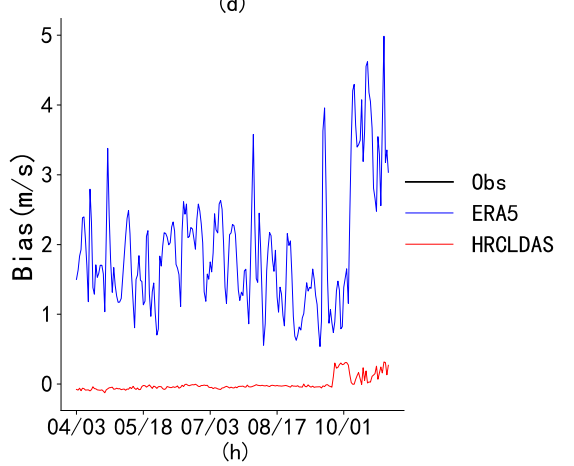

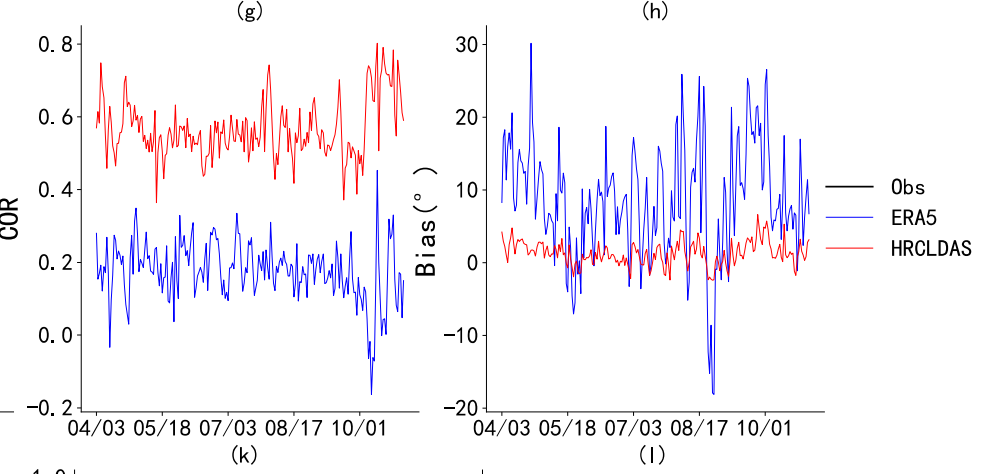
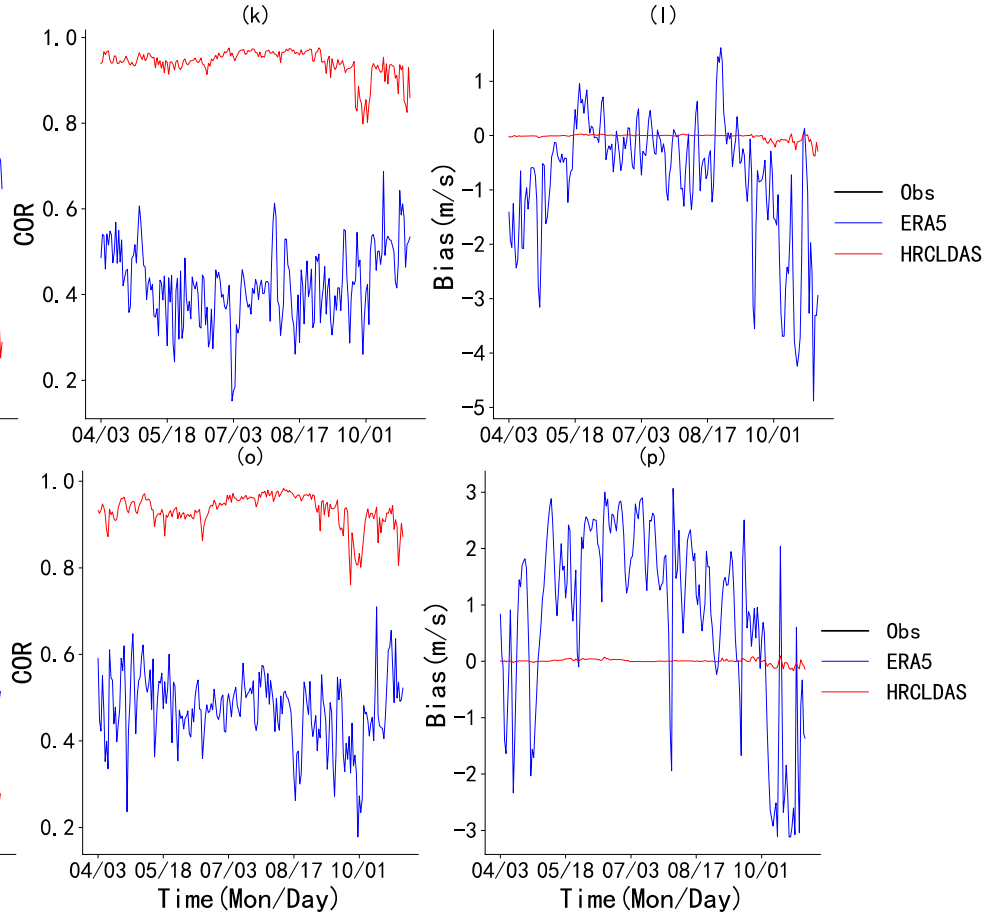

Figure 2. Time series of daily average near-surface (a) wind speed, (e) wind direction, (i) $U$ component, and (m) $V$ component; RMSE time series of (b) wind speed, (f) wind direction, (j) $U$ component, and (n) $V$ component; COR time series of (c) wind speed, (g) wind direction, (k) $U$ component, and (o) $V$ component; bias time series of (d) wind speed, (h) wind direction, (1) $U$ component, and (p) $V$ component.

Figure $2 d, h, l, p$, show the time series diagrams of the daily average bias of wind speed, wind direction, $U$ component, and $V$ component, respectively. The bias of HRCLDAS from April to October was less than that of ERA5. For wind speed, the HRCLDAS data showed a negative bias from April to September, and the bias increased significantly in October, which showed a positive bias. For the wind direction, the bias of HRCLDAS and ERA5 was mostly positive, the bias of HRCLDAS was less than $6^{\circ}$, and the bias of ERA5 varied more dramatically over time, mostly between $0^{\circ}$ and $30^{\circ}$. For the $U$ and $V$ components, 
the bias between HRCLDAS and the observation data were all approximately $0^{\circ}$ without distinct variability. The $U$ component of the ERA5 data showed mostly a negative bias, whereas the $\mathrm{V}$ component mostly showed a positive bias, and the bias of $V$ component was larger than that of the $U$ component.

In general, for daily average wind speed, wind direction, $U$ component, and $V$ component, HRCLDAS was closer to the observations than ERA5, with a lower RMSE, smaller bias, and higher COR.

\subsection{Comparative Analysis of Each Station}

Figure 3 shows a comparison of the RMSE distribution of wind speed, wind direction, $U$ component, and $V$ component between ERA5 and HRCLDAS from April to October for each station of Hainan Island and the South China Sea. For wind speed, from Figure 3a it can be seen that the stations with higher RMSE for ERA5 were mainly distributed in the northeastern part of Hainan Island, and the coastal and South China Sea regions, at about 2.5-4.5 m s${ }^{-1}$. The RMSE in the central and southwestern regions of Hainan Island was relatively small, mostly between 1.4 and $2.0 \mathrm{~m} \mathrm{~s}^{-1}$. From Figure $3 \mathrm{~b}$ it can be seen that the RMSE of the wind speed for HRCLDAS was significantly smaller than that for ERA5, most of the stations are below $1 \mathrm{~m} \mathrm{~s}^{-1}$, and the stations with larger RMSE were mainly distributed in the coastal areas of Hainan Island and some offshore stations. For the wind direction, the RMSE for both ERA5 (Figure 3c) and HRCLDAS (Figure 3d) was low in the coastal and island stations and high in inland stations. The RMSE station distribution characteristics of the $U$ component (Figure $3 \mathrm{e}, \mathrm{f}$ ) and $V$ component (Figure $3 \mathrm{~g}, \mathrm{~h}$ ) were generally similar to that of the wind speed. The stations with a larger RMSE for the $V$ component than the $U$ component for ERA5 were mainly distributed in the coastal areas of Hainan Island. The RMSE for the $U$ and $V$ components of HRCLDAS were similar, and the stations with a lower RMSE for the $V$ component than the $U$ component were mainly distributed in the central and northern parts of Hainan Island.

Figure 4 shows a comparison of the COR distribution of wind speed, wind direction, $U$ component, and $V$ component between ERA5 and HRCLDAS from April to October for each station of Hainan Island and the South China Sea. For wind speed, the stations with a higher ERA5 COR (Figure 4a) were mainly distributed in the east and west coastal areas of Hainan Island and the South China Sea, and the stations with a COR that was lower than 0.4 were mainly distributed in the central part of Hainan Island. Most of the HRCLDAS COR (Figure $4 \mathrm{~b}$ ) were between 0.95 and 1.0, and the stations with low correlation coefficients were mainly in the middle of Hainan Island. For the wind direction, the stations with better ERA5 COR (Figure 4c) were mainly distributed in the northeast of Hainan Island and the South China Sea, while the stations with a low COR were mainly in the middle and south of Hainan Island, and some of the stations had negative correlation. The COR of HRCLDAS wind direction (Figure 4d) was significantly higher than that of ERA5, the COR of most stations in the east and west of Hainan Island was more than 0.8 , and the COR of the stations in the South China Sea was more than 0.9, and the stations with lower COR were mainly in the complex terrain areas, such as central Wuzhishan City. The stations with a higher COR for the $U$ component of ERA5 (Figure 4e) were mainly distributed in the South China Sea and the coast of Hainan Island. The COR for the $V$ component of ERA5 (Figure $4 \mathrm{~g}$ ) was significantly higher than that of the $U$ component in the eastern part of Hainan Island. The station distribution of the COR for the $U$ and $V$ components of HRCLDAS (Figure 4f,h) was similar to that of wind speed, most of them were above 0.95 , and the stations with a low COR appeared in Wuzhishan City. 

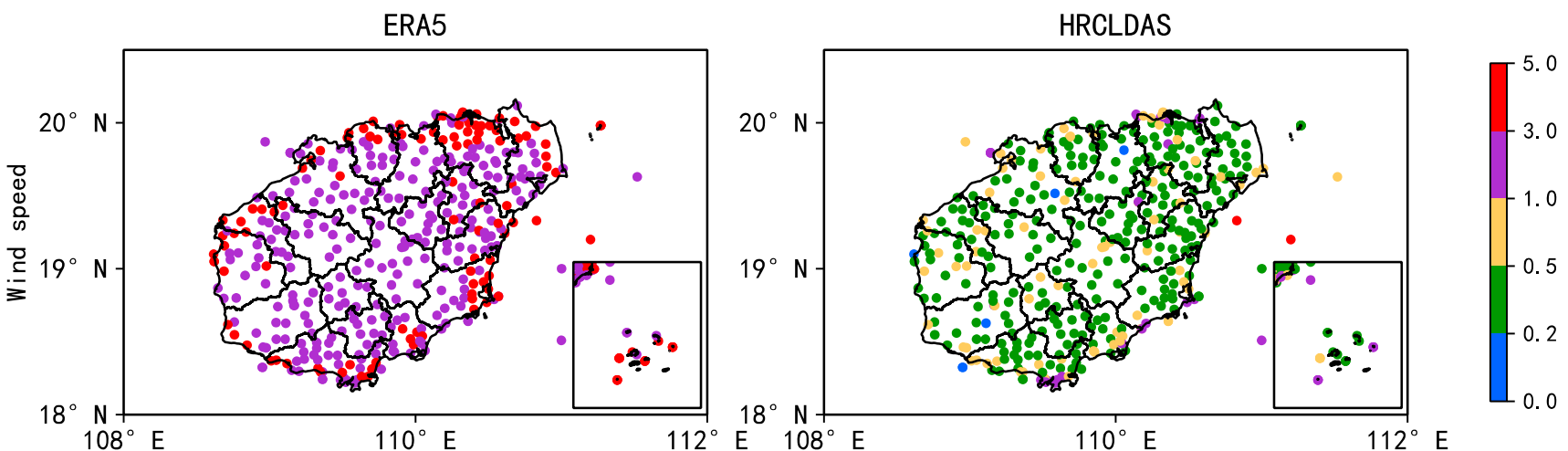

(a)
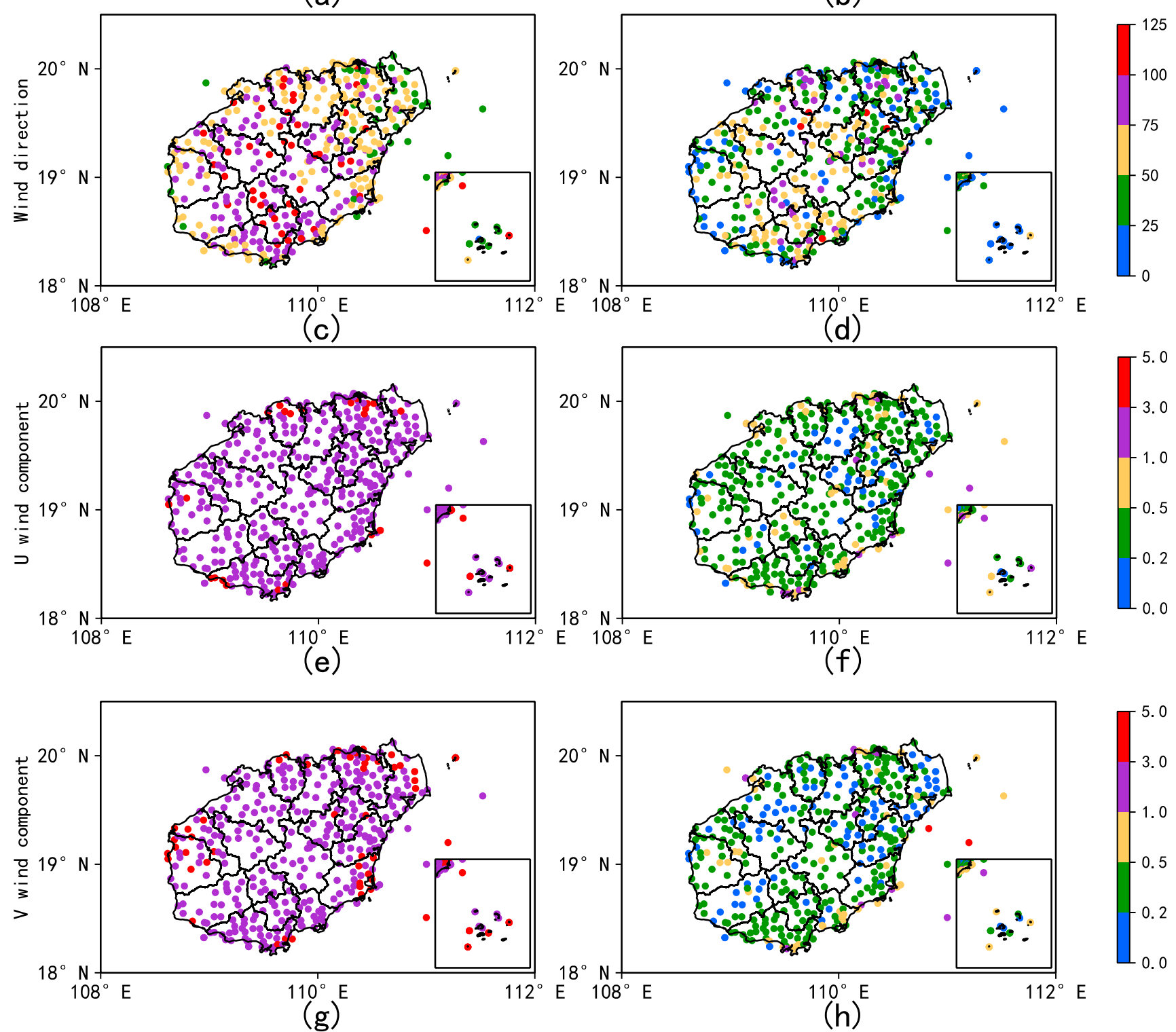

Figure 3. RMSE spatial distribution. (a) ERA5 near-surface wind speed, (c) ERA5 wind direction, (e) ERA5 $U$ component, (g) ERA5 $V$ component; (b) HRCLDAS near-surface wind speed, (d) HRCLDAS wind direction, (f) HRCLDAS U component, and (h) HRCLDAS $V$ component. 


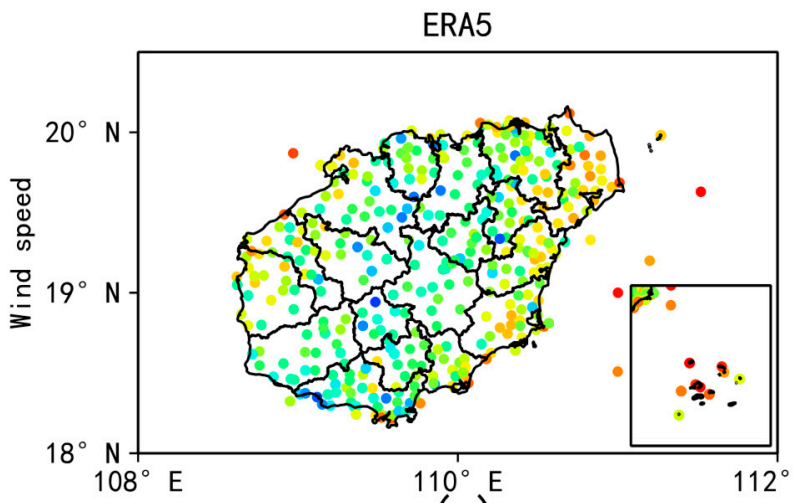

(a)

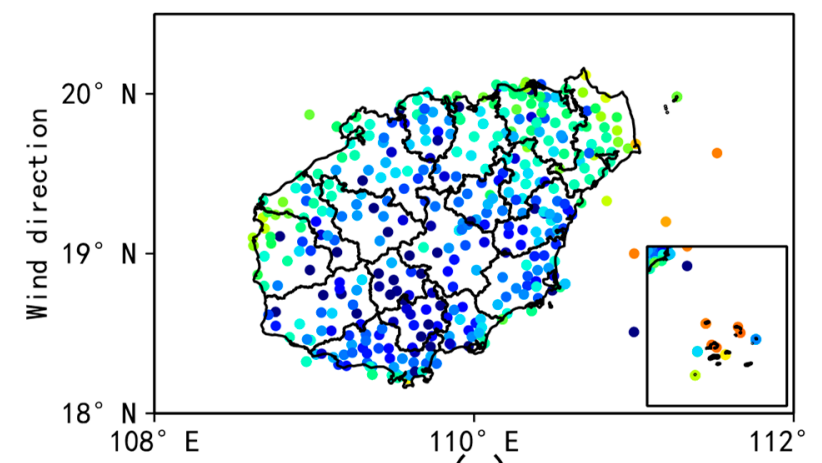

(c)
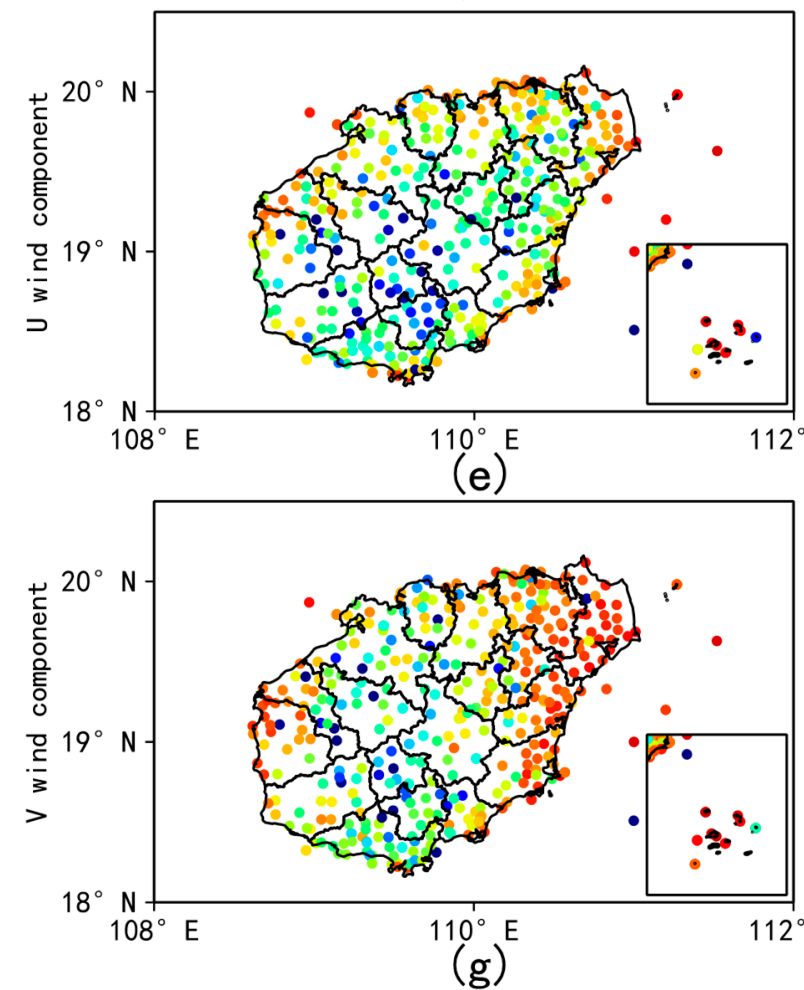

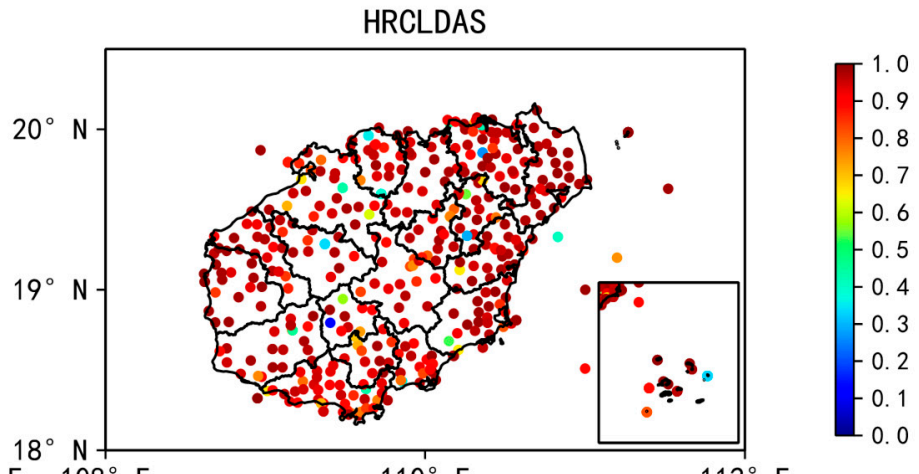

(b)

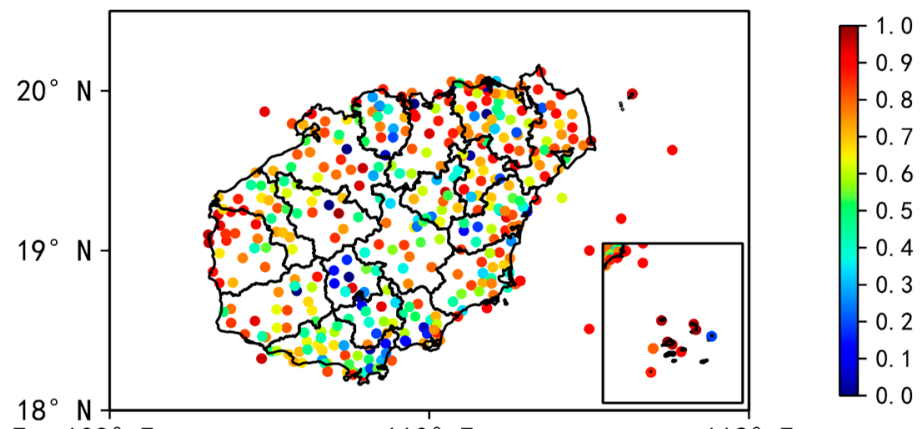

(d)

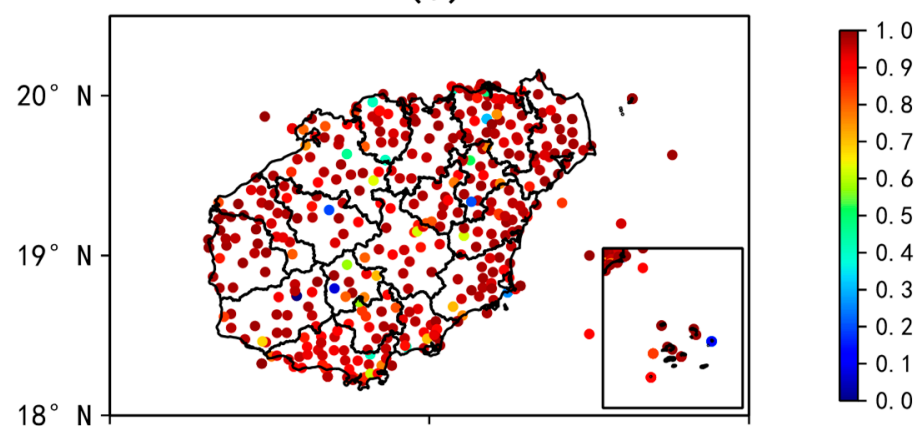

(f)

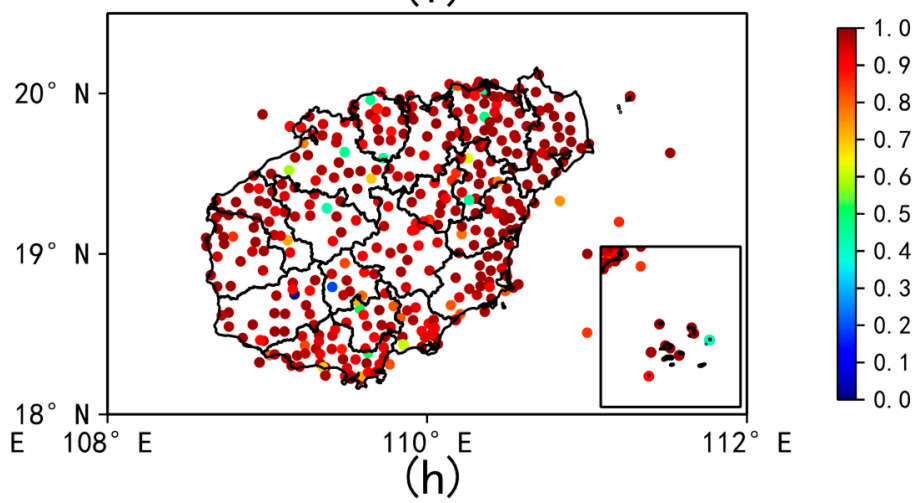

Figure 4. COR spatial distribution. (a) ERA5 near-surface wind speed, (c) ERA5 wind direction, (e) ERA5 U component, (g) ERA5 V component; (b) HRCLDAS near-surface wind speed, (d) HRCLDAS wind direction, (f) HRCLDAS U component, and (h) HRCLDAS $V$ component. 


\subsection{Comparative Analysis of Land and Sea}

The performance of the two wind data products from April to October 2020 for Hainan Island land stations and island stations, respectively, were evaluated to analyze the performance of ERA5 and HRCLDAS wind products over land and sea. There are 70 island stations in Hainan Province, and Figure 5 shows the evaluation results. For wind speed, the bias of ERA5 on land and the islands was $1.91 \mathrm{~m} \mathrm{~s}^{-1}$ and $2.14 \mathrm{~m} \mathrm{~s}^{-1}$, respectively, and the bias of HRCLDAS on land and the islands was $0.01 \mathrm{~m} \mathrm{~s}^{-1}$ and $0.04 \mathrm{~m} \mathrm{~s}^{-1}$, respectively, both of which are positive values. In addition, the bias for land stations was smaller than that for island stations. The RMSE between the two wind speed datasets and observations had the same performance and deviation for the two underlying surfaces, and both are smaller on land than on islands. The correlation coefficients of the two wind speed datasets were similar for land and the islands. The correlation coefficients for ERA5 on land and the islands were 0.53 and 0.52, respectively, and, for HRCLDAS, they were 0.94 and 0.95 , respectively.

(a)
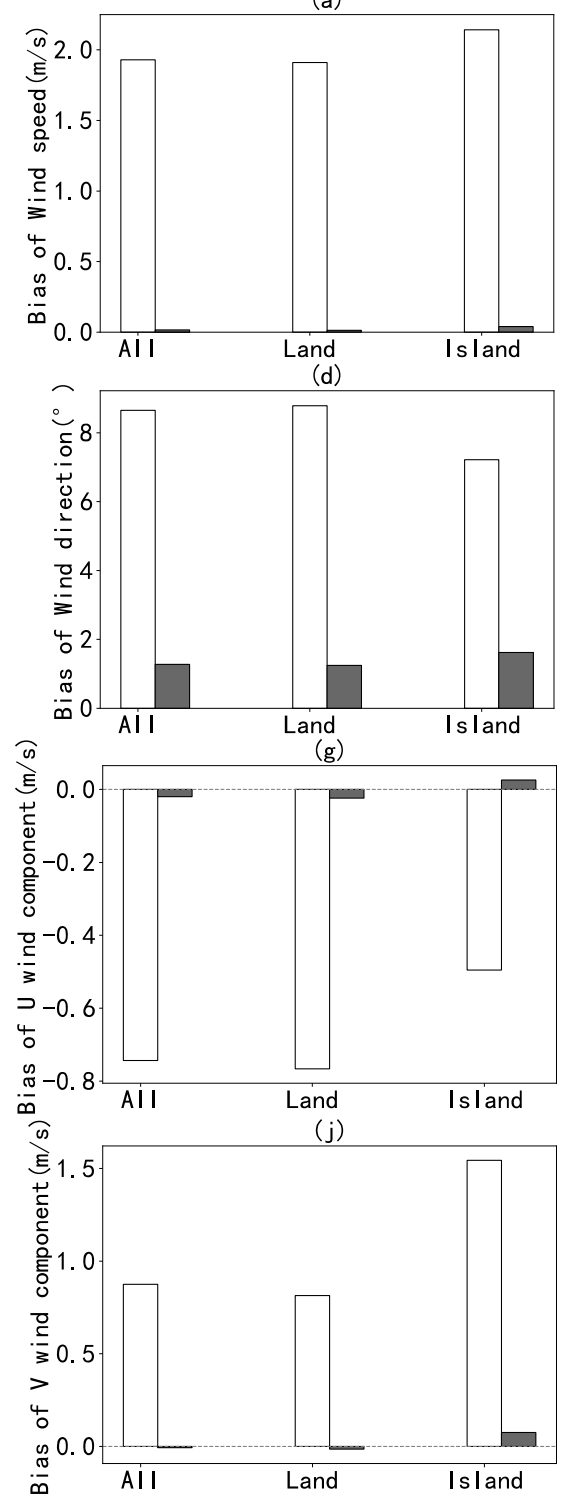

$\square$ ERA5 $\square$ HRCLDAS
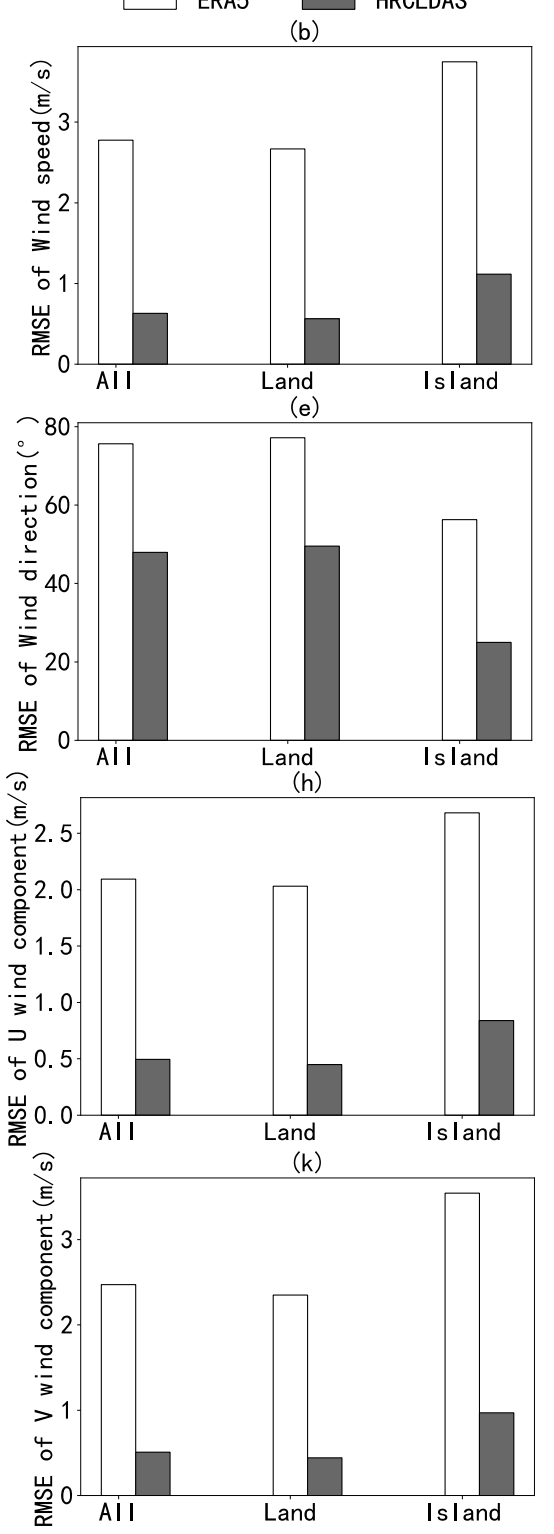

(c)
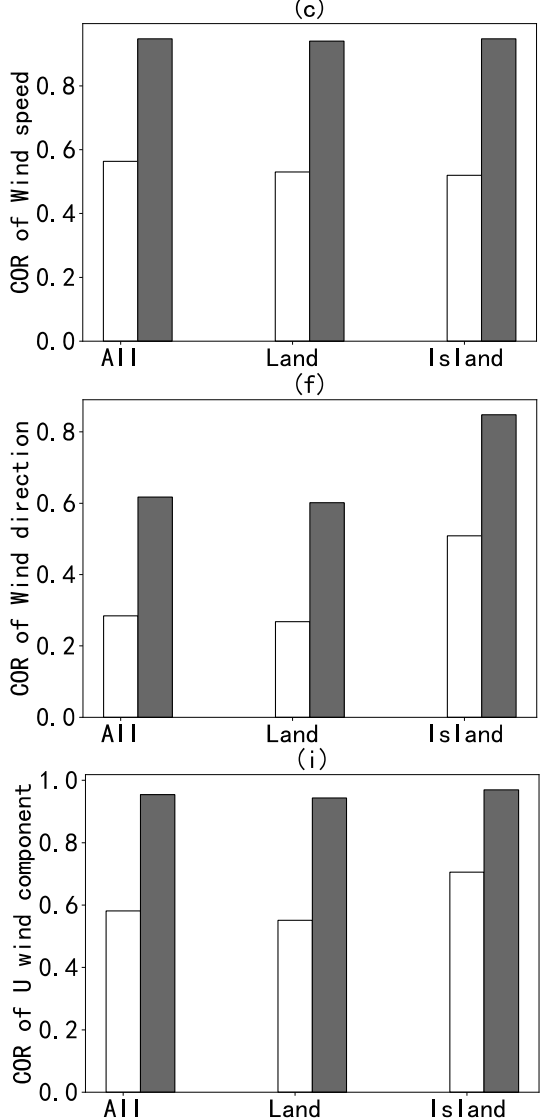

(

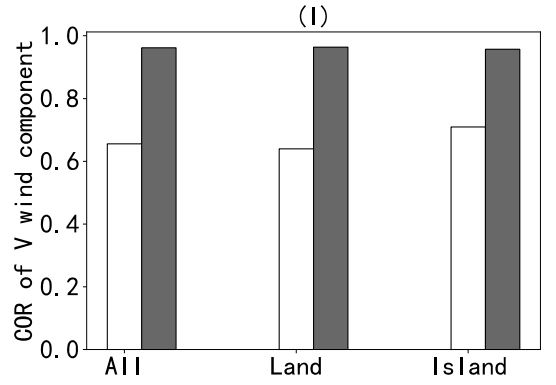

Figure 5. Evaluation indicators of ERA5 and HRCLDAS for land and sea. Bias of near-surface wind speed (a), wind direction (d), $U$ component (g), and $V$ component (j); RMSE of near-surface wind speed (b), wind direction (e), $U$ component (h), and $V$ component (k); COR of near-surface wind speed (c), wind direction (f), $U$ component (i), and $V$ component (l). 
For wind direction, ERA5 and HRCLDAS show a positive bias on land and the islands. The bias of ERA5 on land was higher than that on the islands, which were $8.78^{\circ}$ and $7.22^{\circ}$, respectively. The bias of HRCLDAS on land was slightly smaller than that on the islands, which were $1.24^{\circ}$ and $1.62^{\circ}$, respectively. The RMSEs of the two datasets were smaller on the islands than on land. The RMSEs of ERA5 on land and the islands were $77.2^{\circ}$ and $56.3^{\circ}$, and those of HRCLDAS were $24.9^{\circ}$ and $9.0^{\circ}$. The CORs of ERA5 on land and the islands were 0.27 and 0.51 , respectively, and those of HRCLDAS were 0.60 and 0.85 , respectively.

For the $U$ component, ERA5 had a negative bias on land and the islands, which were $-0.77 \mathrm{~m} \mathrm{~s}^{-1}$ and $-0.50 \mathrm{~m} \mathrm{~s}^{-1}$, respectively, and the bias on land was greater than that on the islands. HRCLDAS had a negative bias on land with a value of $-0.02 \mathrm{~m} \mathrm{~s}^{-1}$, and it had a positive bias on the islands with a value of $0.03 \mathrm{~m} \mathrm{~s}^{-1}$. The RMSE and COR of the two datasets on land were both smaller than on the islands.

For the $V$ component, ERA5 had a positive bias on land and the islands, respectively, with values of $0.81 \mathrm{~m} \mathrm{~s}^{-1}$ and $1.54 \mathrm{~m} \mathrm{~s}^{-1}$, and the bias on land was smaller than that on the islands. The bias of HRCLDAS was similar to that of the $U$ component. The RMSEs of the two datasets were both lower on land than on island stations, and the COR of ERA5 for the land stations were lower than those for the islands, which were $0.64 \mathrm{~m} \mathrm{~s}^{-1}$ and $0.71 \mathrm{~m} \mathrm{~s}^{-1}$, respectively. The COR of HRCLDAS on land was slightly higher than that on the islands, which were 0.964 and 0.957 , respectively.

In general, HRCLDAS wind products had a smaller bias, smaller RMSE, and larger COR for both land and sea islands when compared with ERA5. The quality of the HRCLDAS and ERA5 wind products for islands was slightly better than that for land.

\subsection{Comparative Analysis of Different Landforms}

The landform has a strong influence on the wind, and different physical processes will affect the wind conditions of the stations under different landforms. Owing to the difference between land and sea, the stations that are close to the sea surface will be affected by the sea and land breeze; winds in flat inland areas are influenced by land surface processes and land-atmosphere interactions; the wind in mountainous and hilly areas may be affected by localized circulation that is driven by complex topography $[19,29]$. According to the above situation, the stations on Hainan Island are classified according to their geomorphological characteristics, distance from the station to the sea surface, and altitude (Figure 6): (1) coast stations, if located no further than $10 \mathrm{~km}$ from the sea; (2) inland stations, if located further than $10 \mathrm{~km}$ from the sea and situated on a plain or tableland; (3) hill stations, if located further than $10 \mathrm{~km}$ from the sea and with an altitude between $100 \mathrm{~m}$ and $500 \mathrm{~m}$; and (4) mountain stations, if located further than $10 \mathrm{~km}$ from the sea and with an altitude that is greater than $500 \mathrm{~m}$. Some previous studies have used similar classifications for wind $[19,30]$.

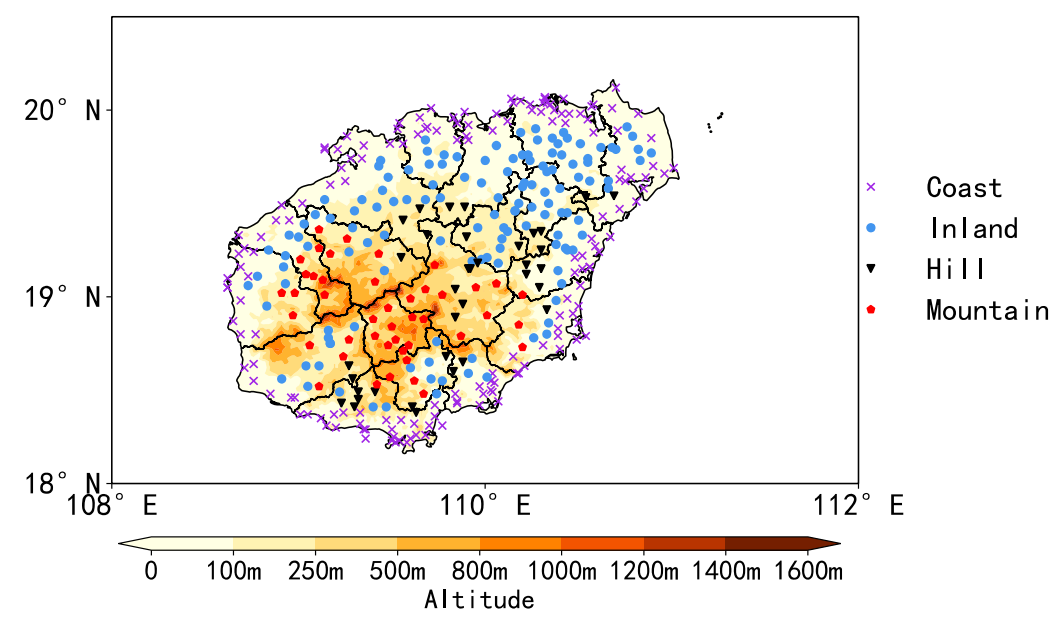

Figure 6. Distribution map of Hainan Island altitude and different landform stations. 
There are 159 coast stations, 135 inland stations, 36 hill stations, and 44 mountain stations on Hainan Island. The quality of ERA5 and HRCRDAS near-surface wind data for different landforms was evaluated and analyzed, and Figure 7 shows the results. Figure 7a-c shows the bias, RMSE, and COR of ERA5 and HRCLDAS wind speed data for the different landforms, respectively. It can be seen that the bias, RMSE, and COR of ERA5 wind speed data decreased in the order of coast, inland, hill, and mountain. The wind speed bias of ERA5 was between 1.1 and $2.3 \mathrm{~m} \mathrm{~s}^{-1}$, the RMSE was between 1.9 and $3.2 \mathrm{~m} \mathrm{~s}^{-1}$, and the COR was between 0.39 and 0.53. The bias and RMSE of HRCLDAS wind speed data for all of the landforms were significantly lower than those for ERA5, and the COR was higher than ERA5. HRCLDAS wind speed data had a slight negative deviation for inland stations, and the rest were positive deviations. The deviation in inland and hilly areas was close to 0 , and the deviation in coastal and mountainous areas was slightly higher than that in inland hills, being around $0.025 \mathrm{~m} \mathrm{~s}^{-1}$; the maximum RMSE occurred on the coast, which was $0.71 \mathrm{~m} \mathrm{~s}^{-1}$, and that of inland, hills, and mountains was not particularly different, approximately $0.4 \mathrm{~m} \mathrm{~s}^{-1}$; the COR did not differ much between different landforms, ranging between 0.93 and 0.96 , with the lowest value in coastal areas.
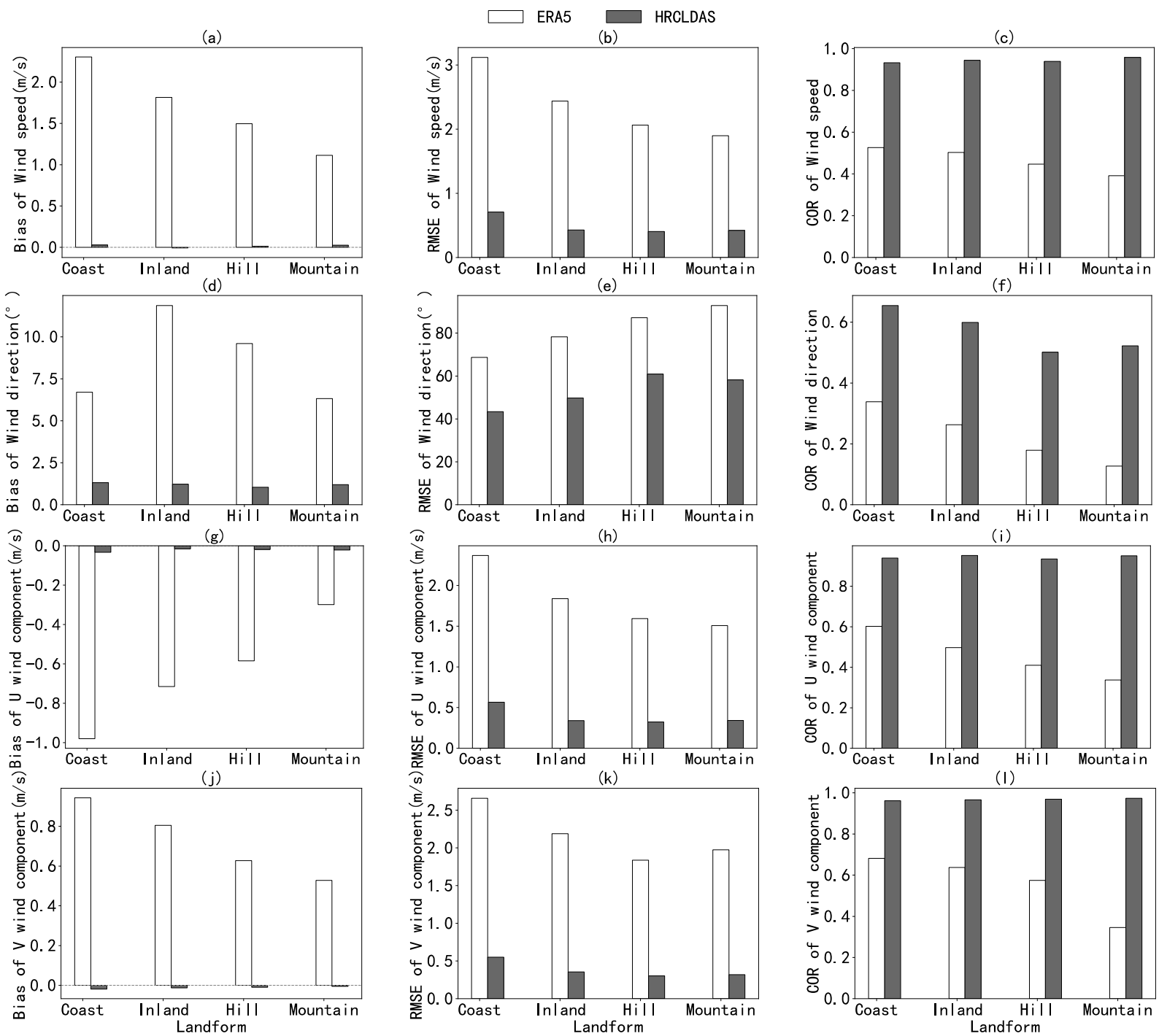

Figure 7. Evaluation indicators of ERA5 and HRCLDAS for different landforms. Bias of near-surface wind speed (a), wind direction (d), $U$ component (g), and $V$ component (j); RMSE of near-surface wind speed (b), wind direction (e), $U$ component (h), and $V$ component (k); COR of near-surface wind speed (c), wind direction (f), $U$ component (i), and $V$ component (1). 
Figure 7d-f shows the bias, RMSE, and COR of ERA5 and HRCLDAS wind direction data for the different landforms. It can be seen that the wind directions of ERA5 and HRCLDAS were positive deviations for the different landforms. The bias of the ERA5 wind direction data was between $6.3^{\circ}$ and $11.9^{\circ}$, with the highest bias occurring inland, followed by hills, and, again, coastal and mountain regions. The bias of the HRCLDAS wind direction data showed little variation for all landforms, ranging from $1.04^{\circ}$ to $1.32^{\circ}$. The RMSE of the ERA5 wind direction data increased in the order of coastal, inland, hilly, and mountainous areas, which ranged from $68.7^{\circ}$ to $92.9^{\circ}$. The RMSE of the HRCLDAS wind direction data was the highest in hilly areas, with a value of $60.9^{\circ}$, which was slightly lower in the mountainous areas, and the lowest in the coastal areas, with a value of $43.4^{\circ}$. The COR distributions for the two kinds of wind direction data for the different landforms correspond to their RMSE distributions. If the RMSE was large, the COR was on the smaller side. The COR of the ERA 5 wind direction data was between 0.13 and 0.34 , the correlation was the lowest in the mountains and highest on the coast, and the correlation of HRCLDAS wind direction data was higher than that of ERA5, ranging from 0.5 to 0.65 , with the lowest being recorded in the hills and the highest on the coast.

Figure $7 g-1$ shows the bias, RMSE, and COR of the $U$ and $V$ wind components for the two datasets. From the bias diagram it can be seen that the $U$ component of ERA5 and HRCLDAS had a negative deviation for all landforms, the $V$ component deviation of ERA5 was positive, and the $V$ component deviation of HRCLDAS was negative; the absolute value of the ERA5 bias decreased in the order of coastal, inland, hilly, and mountainous areas, and the bias of HRCLDAS was close to 0 . The distribution of the other evaluation indicators of the $U$ and $V$ components of ERA5 and HRCLDAS was basically the same as the wind speed, and the quality of the $U$ component of the two datasets was slightly lower than that of the $V$ component.

\subsection{Evaluation of Wind Speed by Grade}

The accuracy, strong rate, and weak rate of the hourly wind grades of ERA5 and HRCLDAS were analyzed on the basis of the wind grade of the hourly observation data. Table 4 shows the statistics of the sample size of each wind grade of the observations from April to October 2020. It can be seen that Grade 1 wind is the largest sample size, and that the sample size decreases with an increasing wind grade. The wind speed data of these two grades were not included in the assessment of this section because of the small number of wind samples of Grade 10 and 11.

Table 4. Sample size of each wind grade from April to October 2020.

\begin{tabular}{cccc}
\hline Wind Grade & Sample Size & Wind Grade & Sample Size \\
\hline 0 & 409122 & 6 & 7159 \\
1 & 574415 & 7 & 2964 \\
2 & 408553 & 8 & 729 \\
3 & 144489 & 9 & 127 \\
4 & 43394 & 10 & 10 \\
5 & 15341 & 11 & 2 \\
\hline
\end{tabular}

Figure 8 shows the wind grade accuracy rate, strong rate, and weak rate of ERA5 and HRCLDAS for different wind grades from April to October. Figure 8a shows the accuracy rate. It can be seen that the accuracy rate of HRCLDAS was higher than that of ERA5 for all wind levels. The highest accuracy rate of ERA5 was $43.9 \%$ for Grade 4 wind, and the accuracy of other wind grades gradually decreased from the left and right sides of the Grade 4 wind. The accuracy rate of HRCLDAS for all wind levels was above $60 \%$, the lowest was $63.8 \%$ for Grade 0 wind, the second lowest was 69\% for Grade 6 wind, the accuracy rate of other the wind power grades increased step by step from the left and right sides of the Grade 6 wind, and Grade 1 wind was the highest, reaching 92.1\%. 


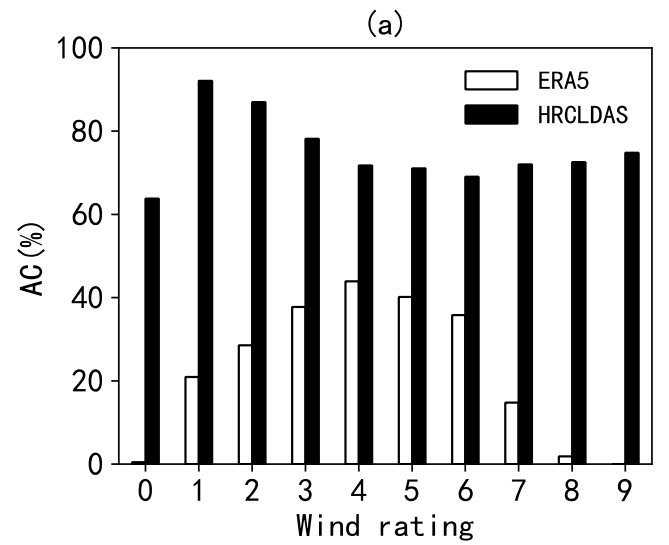

(b)

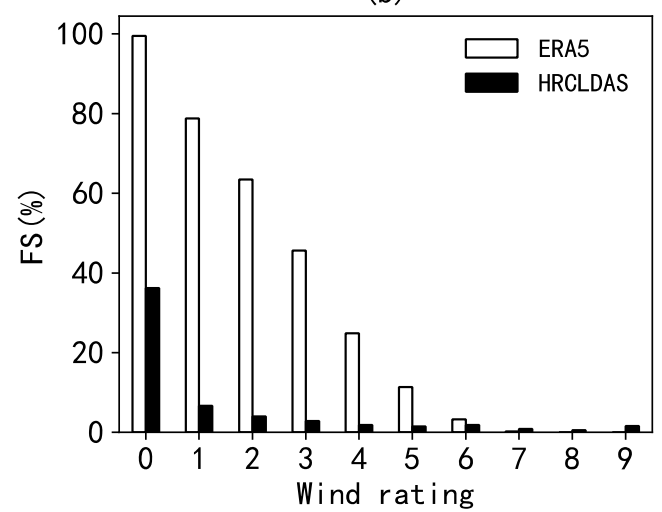

(c)

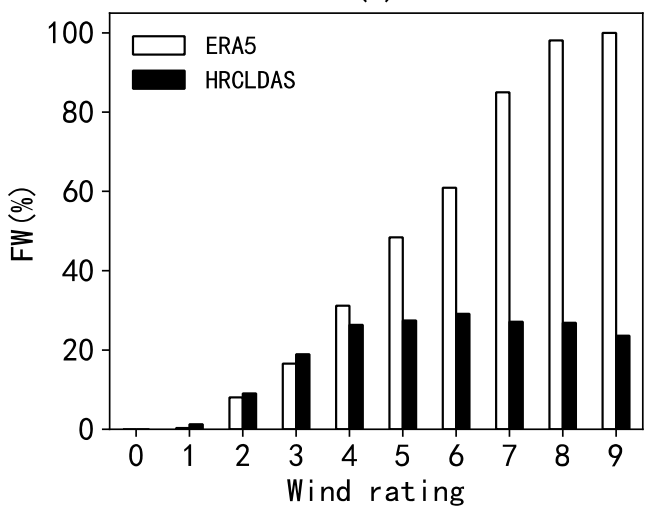

Figure 8. The evaluation indicators of ERA5 and HRCLDAS under various wind levels from April to October 2020: (a) accuracy rate; (b) strong rate; and (c) weak rate.

Figure $8 \mathrm{~b}, \mathrm{c}$ shows the strong rate and weak rate of each wind grade. The strong and weak rates of HRCLDAS were lower than the accuracy. The HRCLDAS wind was more likely to be stronger in Grades 0 and 1, and weaker in other wind grades, when compared with the observations. That means HRCLDAS was more likely to underestimate the wind speed. ERA5 had a relatively high strong rate when the wind grade was between 0 and 3 , and the wind speed of ERA5 was significantly overestimated when compared with observations, especially for the Grade 0 wind, with its strong rate reaching $99.5 \%$. The strong rate of ERA5 decreased with an increasing wind grade. When the wind grade was higher than Grade 5, the weak rate of ERA5 wind was higher than the strong rate and accuracy rate, which indicated that the wind speed was significantly underestimated. With the increase of the wind grade, the weak rate increased, and the highest weak rate was $100 \%$ when the wind grade was 9 .

The accuracy of ERA5 and HRCLDAS at each station under all wind levels was analyzed. Figure 9a shows the distribution of the ERA5 wind accuracy for each station. It can be seen that the stations with an accuracy between 0 and $20 \%$ were mainly distributed in the eastern, northern, and coastal areas of Hainan Island. The wind accuracy rates of offshore stations in the South China Sea were relatively high, while those of some island stations in Xisha were lower than $5 \%$. Figure $9 \mathrm{~b}$ shows the distribution of the HRCLDAS wind accuracy rate for each station. It can be seen that the accuracy rates of HRCLDAS were higher than those of ERA5 for most of the stations. There were 285 stations with an accuracy rate of more than $80 \%$, accounting for $69.3 \%$ of the total number of stations. Most of the stations with a lower accuracy rate were distributed in coastal areas. 


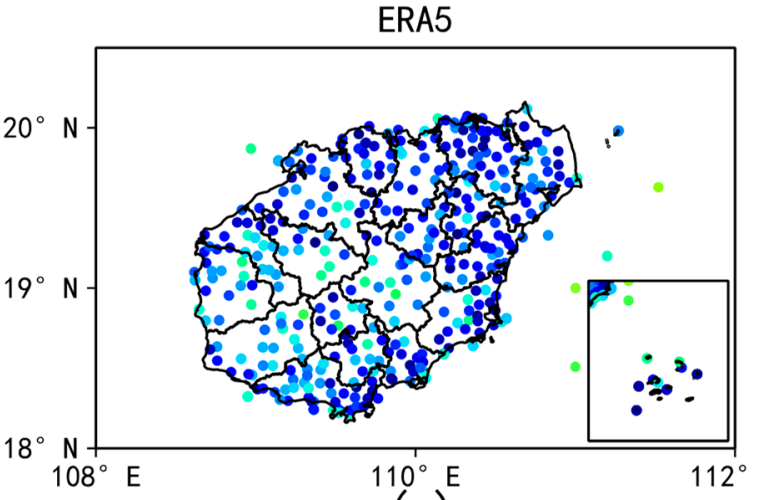

(a)

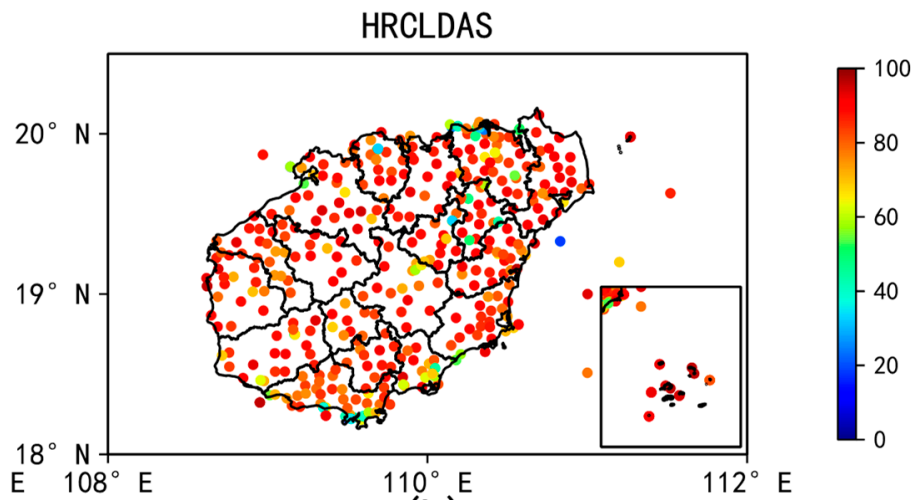

(b)

Figure 9. Spatial distribution of wind force grade accuracy. (a) ERA5; (b) HRCLDAS.

Figure 10 shows the distribution of the accuracy, strong rate, and weak rate of ERA5 and HRCLDAS for the different underlying surfaces for each wind grade from April to October. From Figure 10a,c it can be seen that there was little difference in the accuracy of the ERA5 wind grade between land and the islands. The accuracy rate of Grade 4 wind was the highest, which was $40.7 \%$ and $42.5 \%$ on land and the islands, respectively. The accuracy rate of Grade 1-3 and 5 wind was higher on land than on the islands, and the accuracy rate of Grade 4 and 6-8 wind was higher on the islands than on land. The strong rate of ERA5 on land and the islands decreased with an increasing wind grade, whereas the weak rate showed the opposite, which meant that the ERA5 data were more likely to underestimate high-grade wind speed over land and overestimate low-level wind speed over the ocean.
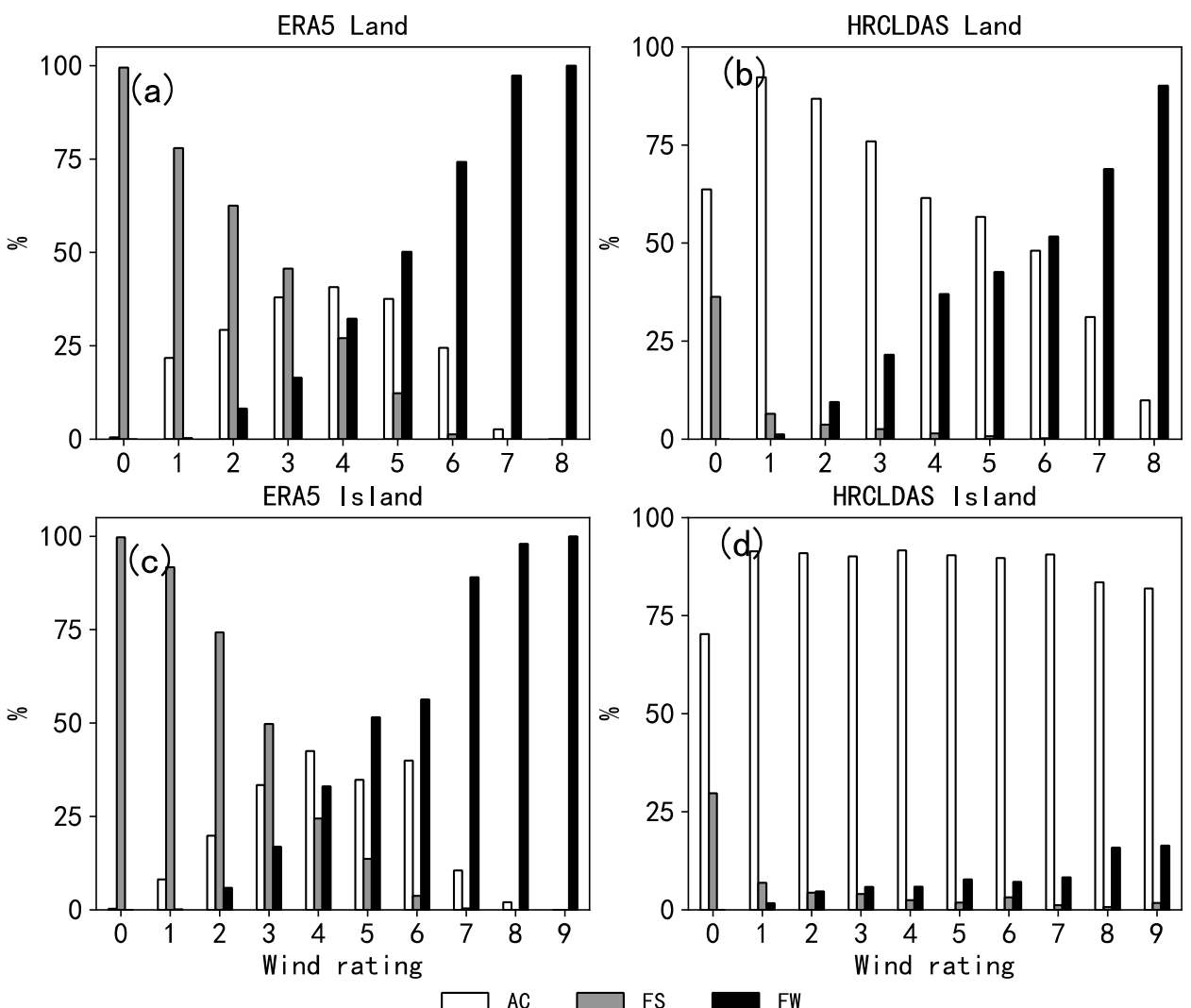

Figure 10. Wind grade accuracy rate, strong rate, and weak rate of ERA5 and HRCLDAS for the different underlying surfaces. (a) ERA5 on land; (b) HRCLDAS on land; (c) ERA5 on islands; and (d) HRCLDAS on islands. 
Figure 10b shows the accuracy of HRCLDAS for each grade of wind force on land. With the exception of Grade 0 wind, the accuracy of the wind grades decreased with the increasing wind grade, and the highest was $92.3 \%$ for Grade 1 . The accuracy rates of Grade $1-5$ wind were more than $56 \%$, and those of Grade 6-8 wind were less than $50 \%$. On land, the strong rates of wind above Grade 1 were low, the weak rates were higher than the strong rates, and the weak rates of Grade 6-8 wind were higher than the accuracy rates. This means that, over land, HRCLDAS underestimated high-grade wind speed, and the higher the wind grade, the more significant the underestimation. Figure $10 \mathrm{~d}$ shows the accuracy rate of HRCLDAS for each grade of wind force on the islands. It can be seen that, except for Grade 0 wind, which had an accuracy rate of $70.3 \%$, the accuracy rates of the wind grades were above $80 \%$, with the lowest being $81.9 \%$ for Grade 9 and the highest being $91.6 \%$ for Grade 4 . On the islands, the strong rates and weak rates were low, and the weak rates were slightly higher than the strong rates. It can be seen that the accuracy rate of HRCLDAS on the islands was significantly higher than that on land, especially for high-grade wind speed.

\subsection{Comparative Analysis of Performance for the Typhoon Process}

A typhoon case was selected to evaluate the performance of the two datasets for the typhoon process in order to analyze the performance of ERA5 and HRCLDAS in special weather processes. Typhoon "Nangka" occurred in October 2020. The period when the typhoon had the greatest impact on Hainan Island and the South China Sea was selected for analysis, which is $12-14$ October.

Figure 11a,b shows the wind vector frequency distribution of ERA5 and HRCLDAS on 12-14 October 2020, respectively. It can be seen that ERA5 had a significant false positive phenomenon in the wind direction of $270^{\circ}-315^{\circ}$, there was clear underreporting between $225^{\circ}$ and $270^{\circ}$, and the probability of not being simulated for high wind speed was high. The wind vector frequency distribution of HRCLDAS was closer to that of the observations, and the simulation of higher wind speeds was more accurate, but there was also the obvious underestimation and underreporting of high wind speeds near the $180^{\circ}$ wind direction.

(a) ERA5

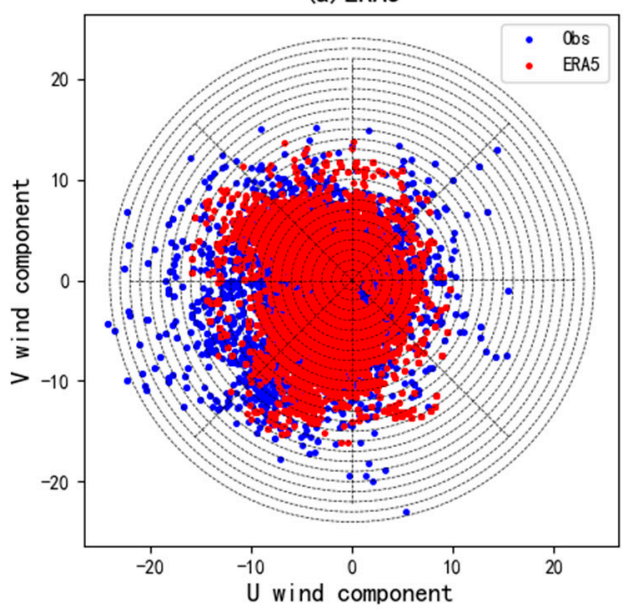

(b) HRCLDAS

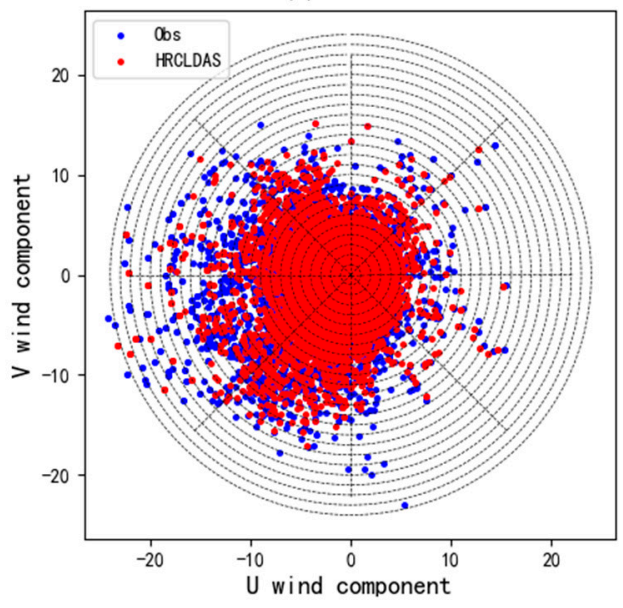

Figure 11. The frequency distribution of wind vector on 12-14 October 2020. (a) ERA5; (b) HRCLDAS.

Several individual stations were selected to compare and analyze the variation of wind speed with time between the two datasets and the observations during the typhoon. Figure 12a depicts a location map of selected sites, which represent an offshore island station, an offshore land station, a remote island station, and a land station. 


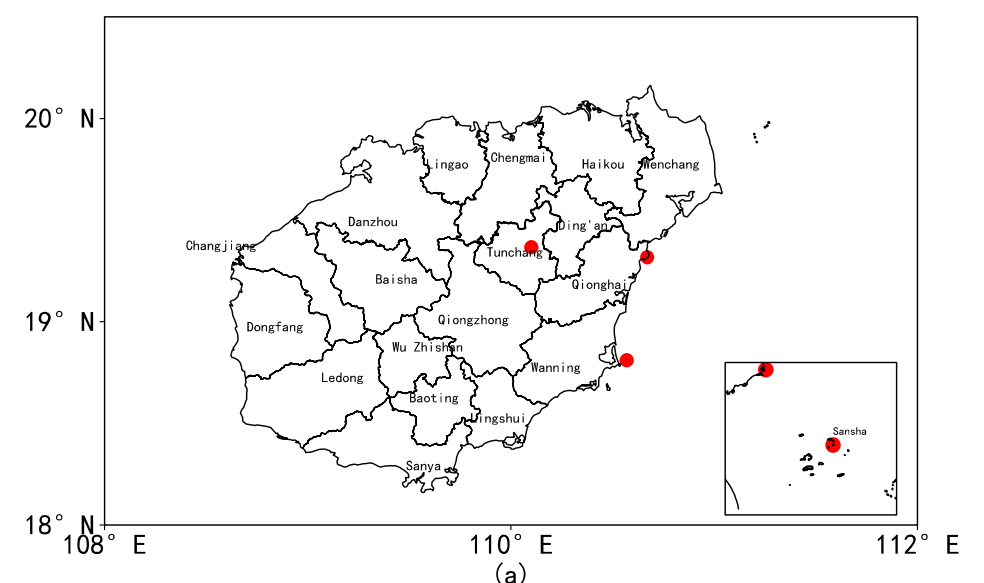

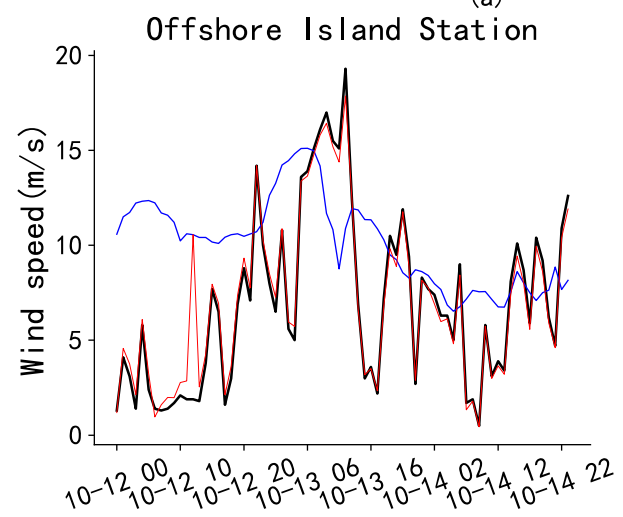

(b)

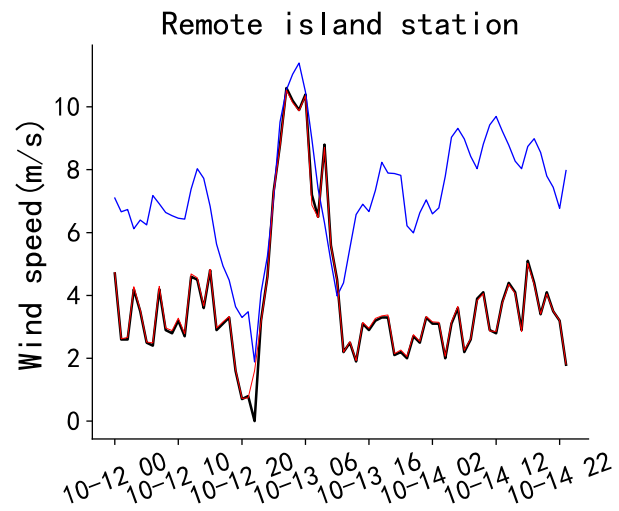

(d) Obs

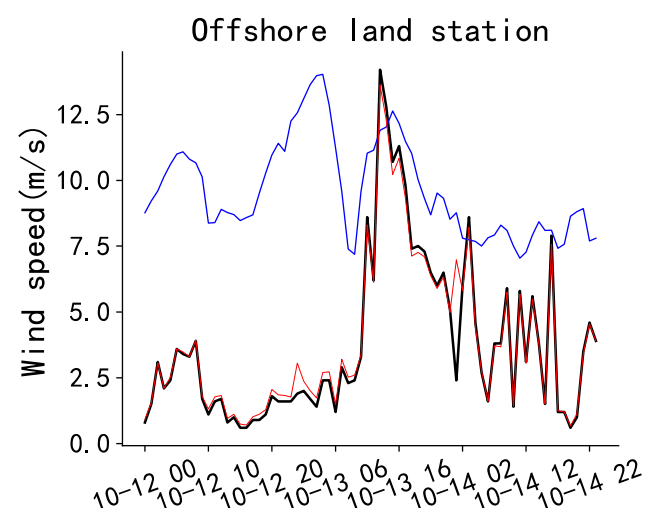

(c)

Land station

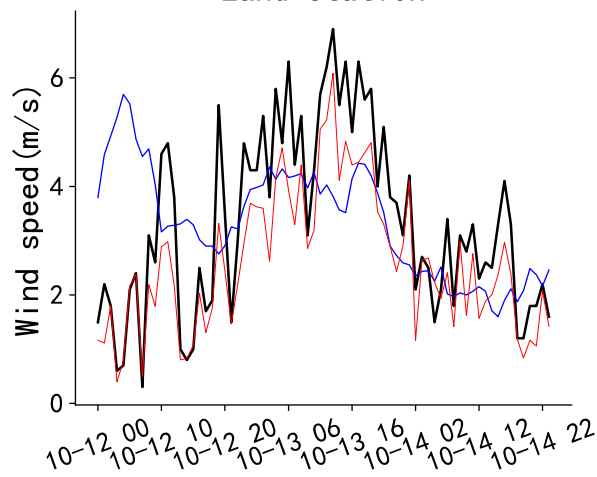

ERA5
HRCLDAS

Figure 12. (a) Location map of example stations. Time series of near-surface wind speed on 12-14 October 2020: (b) offshore island station (Wanning Bai'an Island Station); (c) offshore land station (Qionghai Qingge Port Station); (d) remote Island Station (Xisha Station); and (e) land Station (Tunchang Station).

Figure $12 \mathrm{~b}$ shows the time series of near-surface wind speed at the offshore island station (Wanning Bai'an Island Station). It can be seen that HRCLDAS simulated the wind speed change during the typhoon well, with only a few discrepancies, whereas ERA5 clearly overestimated the low wind speed, underestimated the high wind speed, inaccurately simulated the wind speed change, and did not simulate many sudden wind speed changes.

Figure 12c shows the time series of near-surface wind speed at the offshore land station (Qionghai Qingge Port Station). It can be seen that ERA5 overestimated the wind speed at the offshore land station when compared with the observations, and there was a time offset of the simulation of wind speed variation between ERA5 and the observations. 
The HRCLDAS wind speed was basically consistent with the observations, except at some of the peak values.

Figure $12 \mathrm{~d}$ shows the time series of near-surface wind speed at the remote island station (Xisha Station). At this station, the simulation quality of ERA5 and HRCLDAS was better than that for the other kinds of station. ERA5 mostly simulated the change of wind speed, but there was still a time offset, which was later than the observations as a whole.

Figure 12e shows the time series of near-surface wind speed at the land island station (Tunchang Station). ERA5 roughly simulated the change trend of wind speed at the land station, but without enough detail, and the simulation of the peak time of wind speed was offset. HRCLDAS simulated the change of wind speed at the land station well, but the wind speed value showed a certain deviation.

In general, there was a significant overestimation of low wind speed by ERA5 in the typhoon process, the simulation of the change of wind speed during the typhoon was not accurate, and the time simulation of the peak value was offset. When compared with ERA5, HRCLDAS could better simulate the variation characteristics of the wind speed, and the simulation was the best in the remote islands.

\section{Discussion}

The near-surface wind is a major factor in various industries of economic importance, such as agriculture, fishery, transportation, construction, water conservancy projects, and so on. It is necessary to comprehensively evaluate the performance of near-surface wind products for Hainan Island and the South China Sea. In this study, the nearest-neighbor interpolation method was used to evaluate the quality of ERA5 and HRCLDAS near-surface wind data for Hainan Island and the South China Sea from April to October 2020. The bias, RMSE, COR, and wind grade accuracy rate, strong rate, and weak rate were used as evaluation indexes to analyze the temporal and spatial distribution of these indicators. In addition, the performance of the two datasets during a typhoon was evaluated.

The daily mean values of wind speed, wind direction, $U$ component, and $V$ component of HRCLDAS and ERA5 were basically the same as the observations, but the biases and RMSE of HRCLDAS were smaller, with a higher COR. The variation range of the daily mean value of the four wind products of ERA5 was greater than the observed values.

It can be concluded that the quality of the HRCLDAS and ERA5 wind speed products in the inland of Hainan Island was higher than that in the coastal areas of Hainan Island on the basis of the analysis of the site spatial distribution of the four wind factor evaluation indexes of HRCLDAS and ERA5. This conclusion is consistent with the performance of ERA5 for Guangdong Province in China [23]. The quality of the wind direction products in the coastal areas of Hainan Island was higher than that in the inland. For the wind speed, the RMSEs between the two datasets and the observations on the islands were both larger than on land, but the CORs were similar. For the wind direction, the RMSEs of HRCLDAS and ERA5 on the islands were both smaller than on land, and the CORs were higher on the lands than on land. In general, the data quality of HRCLDAS and ERA5 on the islands in the South China Sea was better than that on land. However, for both land and the islands in the South China Sea, the quality of HRCLDAS was better than that of ERA5, especially in the coastal areas of Hainan Island and the island stations near Sansha, where the quality of HRCLDAS was most significantly better than that of ERA5.

The wind speed RMSE of the ERA5 data was the largest on the coast, the RMSE of wind direction was the largest in the mountain areas, and the CORs were both the smallest in the mountain areas; therefore, it is necessary to be cautious when using ERA5 data for mountain areas. This is consistent with the performance of ERA5 in Sweden [19]. The quality of HRCLDAS near-surface wind data for all of the different landforms was higher than that of ERA5. The quality of the HRCLDAS wind speed data was almost the same for all the different landforms, but it was slightly lower in coastal areas. The quality of the HRCLDAS wind direction had the lowest quality in hilly areas, followed by mountainous areas, which may be due to the complex topography of hilly and mountainous areas. 
From the evaluation results of HRCLDAS and ERA5 for each wind grade, it can be seen that the accuracy rate of HRCLDAS for each grade of wind was higher than that of ERA5. ERA5 significantly overestimated low-grade wind and significantly underestimated high-grade wind, with the highest accuracy rate of $43.9 \%$ for Grade 4 wind. The accuracy rate of HRCLDAS in each wind grade was more than $60 \%$, and its accuracy rate on islands was significantly higher than that on land, especially the accuracy rate of the high-grade wind speed.

The simulation of wind by HRCLDAS was closer to the observations in the process of special weather, such as a typhoon, and the simulation of higher wind speeds was most accurate. In addition, HRCLDAS could better simulate the details of the change of wind speed when compared with ERA5. In contrast, ERA5 had an obvious omission for the simulation of higher wind speeds. ERA5 could simulate the changing trend of wind speed, but the details of the change could not be well simulated, and there was a deviation in the time when the peak wind speed appeared. HRCLDAS and ERA5 both had the best simulation quality for the wind speed for remote island stations.

From the above analysis it can be seen that the quality of HRCLDAS was generally better than the quality of ERA5. The reason for this may be that a multi-grid variational analysis method was adopted for the generation of the HRCLDAS dataset, the background field and the observation field were gradually merged and assimilated from large scale to small scale, and the data that were collected by the automatic wind observation stations were integrated, which ensured the quality of HRCLDAS wind products in China. However, the quality of HRCLDAS near-surface wind data in areas with complex topography and sea-land boundaries still needs to be further strengthened, and how to improve it needs to be further studied.

\section{Conclusions}

This study found that HRCLDAS and ERA5 near-surface wind data can both reflect the general characteristics of wind variation over Hainan Island and the South China Sea. ERA5 near-surface wind speed has a large deviation on the coast; ERA5 overestimates the low-grade wind and underestimates the high-grade wind, and it does not reflect the details of the wind speed change. The quality of the wind direction near the surface for ERA5 is poor, especially in mountainous areas. When compared with ERA5, HRCLDAS near-surface wind data have a lower bias and RMSE from observations, and a higher $\mathrm{COR}$, and it can better reflect higher wind speeds in typhoon weather. However, the near-surface wind speed of HRCLDAS also has a large deviation on the coast, and the quality of wind direction in hilly areas is poor. In general, the quality of HRCLDAS is better than that of ERA5. These differences may be caused by the different data sources and different algorithms. However, there are still some shortcomings in the HRCLDAS data, such as its time series being too short and its coverage being limited to China, which cannot support long-term climate analysis. Therefore, the products should be selected according to actual needs.

Author Contributions: Conceptualization, Y.J. and S.H.; methodology, Y.J. and S.H.; software, Y.J.; validation, X.L.; data curation, S.H.; writing—original draft preparation, Y.J.; writing-review and editing, Y.J., S.H. and T.G.; visualization, Y.J.; supervision, S.H.; project administration, H.Z. and C.S.; funding acquisition, H.Z. and C.S. All authors have read and agreed to the published version of the manuscript.

Funding: This research was funded by the National Key Research and Development Program of China (No. 2018YFC1506601) and the National Meteorological Information Center Project (No. NMICJY202106).

Conflicts of Interest: The authors declare no conflict of interest. 


\section{References}

1. Kunkel, K.E. Simple Procedures for Extrapolation of Humidity Variables in the Mountainous Western United States. J. Clim. 1989, 2, 656-669. [CrossRef]

2. Liu, Z. Comparison of versions 6 and 7 3-hourly TRMM multi-satellite precipitation analysis (TMPA) research products. Atmos. Res. 2015, 163, 91-101. [CrossRef]

3. Yang, F.; Lu, H.; Yang, K.; He, J.; Wang, W.; Wright, J.S.; Li, C.W.; Han, M.L.; Li, Y.S. Evaluation of multiple forcing data sets for precipitation and shortwave radiation over major land areas of China. Hydrol. Earth Syst. Sci. 2017, 21, 5805-5821. [CrossRef]

4. Rolland, C. Spatial and seasonal variations of air temperature lapse rates in Alpine regions. J. Clim. 2003, 16, 1032-1046. [CrossRef]

5. Calisir, E.; Soran, M.B.; Akpinar, A. Quality of the ERA5 and CFSR winds and their contribution to wave modelling performance in a semi-closed sea. J. Oper. Oceanogr. 2021. [CrossRef]

6. Osinski, R.D.; Radtke, H. Ensemble hindcasting of wind and wave conditions with WRF and WAVEWATCH III (R) driven by ERA5. Ocean. Sci. 2020, 16, 355-371. [CrossRef]

7. Ibarra-Berastegi, G.; Gonzalez-Roji, S.J.; Ulazia, A.; Carreno-Medinabeitia, S.; Saenz, J. Calculation of Lebanon offshore wind energy potential using ERA5 reanalysis: Impact of seasonal air density changes. In Proceedings of the 2019 Fourth International Conference on Advances in Computational Tools for Engineering Applications (Actea), Beirut, Lebanon, 3-5 July 2019.

8. Jourdier, B. Evaluation of ERA5, MERRA-2, COSMO-REA6, NEWA and AROME to simulate wind power production over France. Adv. Sci. Res. 2020, 17, 63-77. [CrossRef]

9. Olauson, J. ERA5: The new champion of wind power modelling? Renew. Energy 2018, 126, 322-331. [CrossRef]

10. Taszarek, M.; Kendzierski, S.; Pilguj, N. Hazardous weather affecting European airports: Climatological estimates of situations with limited visibility, thunderstorm, low-level wind shear and snowfall from ERA5. Weather Clim. Extrem. 2020, 28. [CrossRef]

11. Ramon, J.; Lledo, L.; Torralba, V.; Soret, A.; Doblas-Reyes, F.J. What global reanalysis best represents near-surface winds? Q J. Roy. Meteor. Soc. 2019, 145, 3236-3251. [CrossRef]

12. Laurila, T.K.; Sinclair, V.A.; Gregow, H. Climatology, variability, and trends in near-surface wind speeds over the North Atlantic and Europe during 1979-2018 based on ERA5. Int. J. Climatol. 2021, 41, 2253-2278. [CrossRef]

13. Butler, B.W.; Wagenbrenner, N.S.; Forthofer, J.M.; Lamb, B.K.; Shannon, K.S.; Finn, D.; Eckman, R.M.; Clawson, K.; Bradshaw, L.; Sopko, P.; et al. High-resolution observations of the near-surface wind field over an isolated mountain and in a steep river canyon. Atmos. Chem. Phys. 2015, 15, 3785-3801. [CrossRef]

14. Graf, M.; Scherrer, S.C.; Schwierz, C.; Begert, M.; Martius, O.; Raible, C.C.; Bronnimann, S. Near-surface mean wind in Switzerland: Climatology, climate model evaluation and future scenarios. Int. J. Climatol. 2019, 39, 4798-4810. [CrossRef]

15. Oses, N.; Azpiroz, I.; Marchi, S.; Guidotti, D.; Quartulli, M.; Olaizola, I.G. Analysis of Copernicus' ERA5 Climate Reanalysis Data as a Replacement for Weather Station Temperature Measurements in Machine Learning Models for Olive Phenology Phase Prediction. Sensors 2020, 20, 6381. [CrossRef]

16. Kanamitsu, M.; Kistler, R.E.; Reynolds, R.W. NCEP/NCAR reanalysis and the use of satellite data. Adv. Space Res. Ser. 1997, 19, 481-489. [CrossRef]

17. Kobayashi, C.; Endo, H.; Ota, Y.; Kobayashi, S.; Onoda, H.; Harada, Y.; Onogi, K.; Kamahori, H. Preliminary Results of the JRA-55C, an Atmospheric Reanalysis Assimilating Conventional Observations Only. Sola 2014, 10, 78-82. [CrossRef]

18. Dong, X.; Wang, Y.T.; Hou, S.G.; Ding, M.H.; Yin, B.L.; Zhang, Y.L. Robustness of the Recent Global Atmospheric Reanalyses for Antarctic Near-Surface Wind Speed Climatology. J. Clim. 2020, 33, 4027-4043. [CrossRef]

19. Minola, L.; Zhang, F.; Azorin-Molina, C.; Pirooz, A.A.S.; Flay, R.G.J.; Hersbach, H.; Chen, D. Near-surface mean and gust wind speeds in ERA5 across Sweden: Towards an improved gust parametrization. Clim. Dynam. 2020, 55, 887-907. [CrossRef]

20. Rivas, M.B.; Stoffelen, A. Characterizing ERA-Interim and ERA5 surface wind biases using ASCAT. Ocean. Sci. 2019, 15, 831-852. [CrossRef]

21. Zhang, W.; Zhang, H.; Liang, H.; Lou, Y.; Cai, Y.; Cao, Y.; Zhou, Y.; Liu, W. On the suitability of ERA5 in hourly GPS precipitable water vapor retrieval over China. J. Geod. 2019, 93, 1897-1909. [CrossRef]

22. Yu, J.; Zhou, T.J.; Jiang, Z.H.; Zou, L.W. Evaluation of Near-Surface Wind Speed Changes during 1979 to 2011 over China Based on Five Reanalysis Datasets. Atmosphere 2019, 10, 804. [CrossRef]

23. Zheng, Y. A Preliminary Analysis on the Applicability of ERA5 Reanalysis Data in Guangdong Province. Meteorol. Environ. Res. 2020, 11, 41-46.

24. Han, S.; Shi, C.X.; Xu, B.; Sun, S.; Zhang, T.; Jiang, L.P.; Liang, X. Development and Evaluation of Hourly and Kilometer Resolution Retrospective and Real-Time Surface Meteorological Blended Forcing Dataset (SMBFD) in China. J. Meteorol. Res. 2019, 33, 1168-1181. [CrossRef]

25. Shuai, H.; Shi, C.; Jiang, Z.; Xu, B.; Li, X.; Tao, Z.; Jiang, L.; Xiao, L.; Zhi, Z.; Liu, J. Development and Progress of High Resolution CMA Land Surface Data Assimilation System. Adv. Met. SET 2018, 8, 102-108.

26. Wang, C.X.; Graham, R.M.; Wang, K.G.; Gerland, S.; Granskog, M.A. Comparison of ERA5 and ERA-Interim near-surface air temperature, snowfall and precipitation over Arctic sea ice: Effects on sea ice thermodynamics and evolution. Cryosphere 2019, 13, 1661-1679. [CrossRef] 
27. Hoffmann, L.; Gunther, G.; Li, D.; Stein, O.; Wu, X.; Griessbach, S.; Heng, Y.; Konopka, P.; Muller, R.; Vogel, B.; et al. From ERA-Interim to ERA5: The considerable impact of ECMWF's next-generation reanalysis on Lagrangian transport simulations. Atmos. Chem. Phys. 2019, 19, 3097-3124. [CrossRef]

28. Xie, Y.; Koch, S.; McGinley, J.; Albers, S.; Bieringer, P.E.; Wolfson, M.; Chan, M. A Space-Time Multiscale Analysis System: A Sequential Variational Analysis Approach. Mon. Weather Rev. 2011, 139, 1224-1240. [CrossRef]

29. Achberger, C.; Chen, D.; Alexandersson, H. The surface winds of Sweden during 1999-2000. Int. J. Climatol. 2006, 26, 159-178. [CrossRef]

30. Azorin-Molina, C.; Rehman, S.; Guijarro, J.A.; McVicar, T.R.; Minola, L.; Chen, D.; Vicente-Serrano, S.M. Recent trends in wind speed across Saudi Arabia, 1978-2013: A break in the stilling. Int. J. Climatol. 2018, 38, e966-e984. [CrossRef] 